NBER WORKING PAPER SERIES

\title{
TO SEGREGATE OR TO INTEGRATE: EDUCATION POLITICS AND DEMOCRACY
}

\author{
David de la Croix \\ Matthias Doepke \\ Working Paper 13319 \\ http://www.nber.org/papers/w13319
NATIONAL BUREAU OF ECONOMIC RESEARCH
1050 Massachusetts Avenue
Cambridge, MA 02138

August 2007

We thank Sandy Black, Georges Casamatta, Jean Hindriks, Omer Moav, Fabien Moizeau, Vincent Vandenberghe, and seminar participants at Louvain-la-Neuve, Rotterdam, the Stockholm School of Economics, Toulouse, UCLA, and the SED Annual Meeting in Florence for their comments that helped to substantially improve the paper. Simeon Alder and David Lagakos provided excellent research assistance. David de la Croix acknowledges financial support from the Belgian French speaking community (grant ARC 99/04-235) and the Belgian Federal Government (grant PAI P5/21). Matthias Doepke acknowledges support from the National Science Foundation (grant SES-0217051) and the Alfred P. Sloan Foundation. The views expressed herein are those of the author(s) and do not necessarily reflect the views of the National Bureau of Economic Research.

(C) 2007 by David de la Croix and Matthias Doepke. All rights reserved. Short sections of text, not to exceed two paragraphs, may be quoted without explicit permission provided that full credit, including (c) notice, is given to the source. 
To Segregate or to Integrate: Education Politics and Democracy

David de la Croix and Matthias Doepke

NBER Working Paper No. 13319

August 2007

JEL No. H42,H52,I22,O10

\begin{abstract}
The governments of nearly all countries are major providers of primary and secondary education to their citizens. In some countries, however, public schools coexist with private schools, while in others the government is the sole provider of education. In this study, we ask why different societies make different choices regarding the mix of private and public schooling. We develop a theory which integrates private education and fertility decisions with voting on public schooling expenditures. In a given political environment, high income inequality leads to more private education, as rich people opt out of the public system. More private education, in turn, results in an improved quality of public education, because public spending can be concentrated on fewer students. Comparing across political systems, we find that concentration of political power can lead to multiple equilibria in the determination of public education spending. The main predictions of the theory are consistent with state-level and micro data from the United States as well as cross-country evidence from the PISA study.

David de la Croix

IRES - Université catholique de Louvain

Place Montesquieu 3

B-1348 Louvain-la-Neuve, Belgium

david.delacroix@uclouvain.be

Matthias Doepke

University of California, Los Angeles

Department of Economics

405 Hilgard Avenue

Los Angeles, CA 90095-1477

and NBER

doepke@econ.ucla.edu
\end{abstract}




\section{Introduction}

Public schooling is one of the most pervasive social policies around the world today. Starting with industrializing European nations in the nineteenth century, nearly all countries have introduced compulsory schooling laws and public funding of education. However, despite the near universal involvement of the government, private and public funding of education continue to coexist. The share of private education funding varies greatly across countries, from only 1.9 percent of total spending in Norway, to 44.5 percent in Chile (1998, see Section 6). Institutional arrangements concerning the funding of private schools also differ across countries. Private schools can be partly supported by the government as in France or New Zealand, or even entirely publicly funded as in Belgium, or rely exclusively on private funding as in the United States (Toma 1996).

Recently, the OECD Programme for International Student Assessment (PISA), which assesses the knowledge and skills of 15-year-old students in a cross-section of countries, has sparked an intense debate on the relative merits of different education systems. A central question in this debate is why education systems differ so much across countries in the first place. Are there particular country characteristics that explain the choice of an integrated education system instead of a regime with segregation between public and private schools? Why is it that countries that appear similar in their overall characteristics sometimes end up with widely different education systems? What role does the distribution of political power in a country play for education politics?

The aim of this study is to provide a positive theory of education systems that can be used to address these questions. We develop an analytically tractable framework that integrates political determination of the quality of public schools with private education and fertility decisions. Parents have the choice of sending their children to tax-financed public schools or, alternatively, to opt out of the public system and provide private education to their children. A key feature of our political economy setup is that it allows for bias in the political system, in the sense that the weight of a certain group of voters in political decision making may be larger or smaller that its relative size in the population. In particular, we contrast outcomes under an even distribution of political power, such as in a represen- 
tative democracy, with outcomes when a political bias gives a disproportionate share of power to the rich.

We find that when political power is evenly distributed, a unique political equilibrium exists. Perhaps not surprisingly, the extent of public versus private funding depends on the income distribution. Parents decide to send their children to a private school if they would like to endow their children with an education of a much higher quality than what is provided by the public system. In a society with little inequality, the preferred education level varies little in the population, so that all parents use public schooling. For increasing levels of inequality, an increasing share of richer people chooses private education for their children. ${ }^{1}$

In our model, the ultimate motive behind public education provision is redistribution. At first sight, one might expect that the equilibrium tax rate should increase with inequality, because a widening income distribution implies a greater demand for redistribution. However, this demand effect is counteracted by an opposing force: as inequality increases, more and more parents opt out of the public system entirely, reducing the funding requirements for public schooling. The latter effect turns out to dominate, so that the tax rate declines with inequality. This result provides a contrast to a literature where a greater degree of inequality motivates more redistribution through higher taxes (see Alesina and Rodrik 1994, Persson and Tabellini 1994, and in particular Gradstein and Justman 1997 in an application to education).

Bénabou (2000), among others, has pointed out that in the data, more unequal countries tend to redistribute less. Our model provides a rationale for this empirical finding. Bénabou (2000) also develops a model that is consistent with this observation, albeit through a different mechanism. In his setup, political participation increases with income. When inequality rises, the decisive voter is richer and decides for less redistribution. The opting-out decision in our model provides an alternative to Bénabou's mechanism. There is, however, a crucial difference between the two theories. In our model, an increase in inequality actually improves the welfare of a poor agent of a given income, even though total tax revenue declines. This is possible because the quality of public schooling

\footnotetext{
${ }^{1}$ This echoes the result of Besley and Coate (1991). Assuming that quality is a normal good, households who opt out of the public sector are those with higher incomes.
} 
improves: the number of students who use public schools declines faster with inequality than overall tax revenue, implying that the funding level per student increases. Thus, even though an increase in inequality reduces the total amount of redistribution, the transfers to public-school parents become more targeted, leaving the poor better off.

Another novel feature of our analysis concerns the efficiency properties of public education. In our theory, fertility decisions are endogenous. Consistent with empirical evidence, the theory predicts that poorer parents who use public schools have more children than parents who choose costly private schools. By raising their fertility rate relative to what they choose if they had to pay for their children's education, the public-school parents impose a fiscal externality on all taxpayers. This externality would not be present in a model with fixed fertility.

The results described so far, pertaining to democratic countries with an even distribution of political power, do not yet offer an explanation for why sometimes countries with similar general characteristics end up with very different education systems. This changes once we introduce bias into the political system. If political power is concentrated among the rich, as in many dictatorships, multiple equilibria with different education systems can arise. In particular, a given population may choose either a high quality of public education with everyone participating in the public system, or a low quality of public education with the rich sending their children to private schools. The source of multiplicity is a complementarity between the rich voters' choice of whether to participate in public education, and their preferred quality of public schools. Interestingly, this complementarity works entirely through the political system. Previous authors have emphasized peer effects as a source of strategic complementarities in education, which we abstract from here. ${ }^{2}$

At first sight, the multiplicity-of-equilibria result may seem to suggest that countries with a biased political system can experience frequent and sudden shifts in the makeup of their education systems. However, a more appropriate realworld interpretation of this result is path dependence and persistence of educa-

\footnotetext{
${ }^{2}$ Variable political power also plays a role for the multiple steady-state result in Bénabou (2000), although the mechanism is entirely different.
} 
tion regimes in such countries. ${ }^{3}$ The multiplicity result relies on the assumption that voters commit to their fertility and schooling regime choices (i.e., public or private) before the electorate determines the quality of public schooling. By committing to their choices, the voters create groups with specific interests for or against public education that are fixed ex post. It is these fixed long-term choices that give rise to self-fulfilling expectations regarding the quality of public schooling.

To assess the empirical content of the multiplicity result, one therefore needs to consider the degree to which the households in a given country are locked into particular fertility or schooling choices. Fertility clearly is an irreversible choice that has to be made years before children enter a school. The reversibility of the schooling choice, in contrast, may vary substantially across countries or regions. If, for example, educational segregation is linked to residential segregation, switching from a private to a public school would also require moving to a different neighborhood or city. This implies high switching costs that lock households into a particular choice for extended periods. In such a country, we would expect the schooling regime to persist over time. If, on the other hand, public and private schools were located right next to each other in the same neighborhoods, switching costs would be less of an issue.

The main predictions of our theory are consistent with a set of stylized facts on public and private schooling in the U.S. as well as in a cross section of countries. For the U.S., we document that states with higher inequality have a larger share of private schooling, less overall spending on public schooling, but a higher quality of public schooling. At the micro level, fertility is decreasing and the probability of using private schools is increasing in income. Moreover, the slope of the income-fertility relationship is flatter in states with a higher quality of public schooling. Similar findings are obtained in cross-country data. Using micro data from the OECD PISA program, we confirm that in a large set of countries highincome households are more likely to use private education, while their fertility rates are lower. Comparing across countries, high inequality is associated with a larger share of private schooling. Concerning the role of political power, we turn

\footnotetext{
${ }^{3}$ The model presented here does not have an explicit dynamic structure; dynamics are discussed in the working paper version of this paper, de la Croix and Doepke (2003b).
} 
to the relationship between democracy and education funding. If we interpret democracies as countries with an even distribution of political power, while nondemocracies are biased to the rich, our model implies that there is more scope for variation in education systems in non-democracies than in democracies. Indeed, using a cross section of 158 countries, we find that the variance of public spending across countries is smaller for democracies than for non-democracies.

Our paper relates to different branches of the literature. A number of authors have addressed the choice of public versus private schooling within a majority voting framework (see Stiglitz 1974, Glomm and Ravikumar 1998, Epple and Romano 1996b, and Glomm and Patterson 2002). A recurring theme in this literature is the argument that if there are private alternatives to public schools, voters' preferences may not be single-peaked, so that a majority voting equilibrium may fail to exist. In contrast, we rely on probabilistic voting as the political mechanism, which yields a fully tractable theory of education regimes in which voting equilibria are guaranteed to exist. Moreover, our probabilistic voting setup is not restricted to democracies, since we can analyze what happens if the political system is biased to the rich. The second main departure from the existing literature is that we endogenize fertility decisions, which leads to novel implications for uniqueness and efficiency properties of equilibria.

Our model makes predictions for the link between inequality in a country and the resulting education system and quality of education. A similar objective is followed by Fernández and Rogerson (1995), who consider a model where education is discrete (zero or one), partially subsidized by the government, and voters decide on the extent of the subsidy. Fernández and Rogerson emphasize that in unequal societies, the poor may forgo education entirely. Since all voters are taxed, in this case public education constitutes a transfer of resources from the poor and the rich to the middle class, echoing the findings of Epple and Romano (1996a). While these arguments are highly relevant for the case of post-secondary education, at the primary and secondary level participation rates are high even for poor children in most countries. Thus, at these levels the choices that we model here (private versus public education and the quality of public education) may be the more important margins.

A different branch of the literature takes the schooling regime (public or private) 
as given, and analyzes the economic implications of each regime. Glomm and Ravikumar (1992) contrast the effects of public and private schooling systems on growth and inequality. In a country with little inequality, a fiscal externality created by public schooling leads to lower growth under public schooling than under private schooling. In unequal societies, however, public schooling can dominate, since more resources are directed to poor individuals with a high return on education. Similar conclusions are derived by de la Croix and Doepke (2004) in a framework which emphasizes the interdependence of fertility and education decisions of parents. The model of Glomm and Ravikumar (1992) has been extended by Bénabou (1996) to allow for local interactions between agents, such as neighborhood effects and knowledge spillovers. Our work advances over these papers by endogenizing the choice of the schooling regime as a function of the income distribution and the political system.

In the next section, we introduce our model and analyze the political equilibrium. Section 3 describes how in a democratic country the choice of a schooling regime and the quality of schooling depend on the income distribution. Section 4 generalizes the voting process to allow for unequal political power. We show that multiple equilibria can arise in societies dominated by the rich. In Section 5 we analyze alternative timing assumptions. In Section 6 we confront the testable implications of the model with empirical evidence. Section 7 concludes. All proofs are contained in the mathematical appendix.

\section{The Model Economy}

\subsection{Preferences and technology}

The model economy is populated by a continuum of households of measure one. Households are differentiated by their human capital endowment $x$, where $x$ is the wage that a household can obtain in the labor market. People care about consumption $c$, their number of children $n$, and their children's education $h$. The 
utility function is given by: ${ }^{4}$

$$
\ln (c)+\gamma[\ln (n)+\eta \ln (h)] .
$$

Notice that parents care both about child quantity $n$ and quality $h$. The parameter $\gamma \in \mathbb{R}_{+}$is the overall weight attached to children. The parameter $\eta \in(0,1)$ is the relative weight of quality. ${ }^{5}$ As we will see below, the tradeoff between quantity and quality is affected by the human capital endowment of the parent and by the schooling regime.

To attain human capital, children have to be educated by teachers. The wage of teachers equals the average wage in the population, which is normalized to one. ${ }^{6}$ Parents can choose from two different modes of education. First, there is a public schooling system, which provides a uniform education $s$ to every student. Education in the public system is financed through an income tax $v$; apart from the tax, there are no direct costs to the parents. The schooling quality $s$ and the tax rate $v$ are determined through voting, to be described in more detail later. Parents also have the possibility of opting out of the public system. In this case, parents can freely choose the education quality $e$, but they have to pay the teacher out of their own income. Since education $e$ is measured in units of time of the average teacher, the total cost of educating $n$ children privately is given by ne. We assume that education spending is tax deductible. While tax deductibility of education expenditures varies across countries, deductibility simplifies the analysis because it implies that taxation does not distort the choice between quantity and quality of children. ${ }^{7}$ Apart from the education expenditure, raising one child also takes fraction $\phi \in(0,1)$ of an adult's time. The budget constraint for an adult with

\footnotetext{
${ }^{4}$ The logarithmic utility function is chosen for simplicity; any utility function representing homothetic preferences over the bundle $(c, n, h)$ would lead to the same results. Also, while we focus on a static framework here, the working paper version of this paper extends the analysis to a dynamic setting where today's children are tomorrow's adults.

${ }^{5}$ The parameter $\eta$ cannot exceed 1 because the parents' optimization problem would not have a solution. More specifically, utility would approach infinity as parents choose arbitrarily high levels of education and arbitrarily low levels of fertility. A similar condition can be found in Moav (2005).

${ }^{6}$ The important assumption here is that the cost of education is fixed, i.e., all parents face the same education cost regardless of their own wage. The level of the teacher's wage is set to the average wage for convenience.

${ }^{7}$ The same result would obtain if parents educated their own children (or at least had the option to do so), because then the parent's teaching efforts would reduce their taxable income.
} 
wage $x$ is given by:

$$
c=(1-v)[x(1-\phi n)-n e] .
$$

Education is thus either private, $e$, or public, $s$. Effective education can be expressed as the maximum of the two: $h=\max \{e, s\}$. Of course, parents who prefer public education will choose $e=0$.

Substituting the budget constraint (2) into the utility function (1) allows rewriting the utility of a given household as:

$$
u[x, v, n, e, s]=\ln (1-v)+\ln (x(1-\phi n)-n e)+\gamma \ln n+\gamma \eta \ln \max \{e, s\} .
$$

The consumption good is produced by competitive firms using labor as the only input. We assume that the aggregate production function is linear in effective labor units. The production setup does not play an important role in our analysis; the advantage of the linear production function is that the wage is fixed.

\subsection{Timing of events and private choices}

The level of public funding for education $s$ is chosen by a vote among the adult population. The voters' preferences depend on their optimal fertility and education choices ( $n$ and $e$ ), which are made before voting takes place. In making these choices, agents have perfect foresight regarding the outcome of the voting process. This timing is motivated by the observation that public education spending can be adjusted frequently, while fertility cannot. Similarly, the choice between public versus private education entails substantial switching costs, especially when educational segregation is linked to residential segregation. ${ }^{8}$

At given expected policy variables $v$ and $s$, the utility function $u$ is concave in $n$. Within each group, some agents may choose public schooling, in which case their fertility rate is denoted $n^{s}$, while others opt for private education; fertility for those in private schools is denoted as $n^{e}$. All parents planning to send their

\footnotetext{
${ }^{8}$ In Section 5 we will explore the implications of alternative timing assumptions.
} 
children to the public school choose the same fertility level:

$$
n^{s}=\arg \max _{n} u[x, v, n, 0, s]=\frac{\gamma}{\phi(1+\gamma)} .
$$

Fertility is constant because the income and substitution effects exactly offset each other. On the one hand, richer parents would prefer to have more children, but on the other hand the opportunity cost of raising children is also higher.

The households planning to provide private schooling chose:

$$
\begin{aligned}
n & =\arg \max _{n} u[x, v, n, e, s]=\frac{x \gamma}{(1+\gamma)(e+\phi x)}, \\
e[x] & =\arg \max _{e} u[x, v, n, e, s]=\frac{\eta \phi x}{1-\eta} .
\end{aligned}
$$

Private spending on education depends positively on the wage $x$. Since the basic cost of children is a time cost, having children is expensive for skilled parents. In contrast, the cost of educating children is a resource cost, which is more affordable for skilled, high-income parents. Hence, they have a comparative advantage in terms of raising educated children (as in Moav (2005)).

Notice that $e$ is independent of the outcome of the voting process, implying that the timing of choosing $e$ does not affect the results (in contrast, we will see in Section 5 that the timing of choosing between public and private schooling does matter). Replacing the optimal value for $e[x]$ in the fertility equation we find:

$$
n^{e}=\frac{\gamma(1-\eta)}{\phi(1+\gamma)}
$$

Thus, conditional on choosing private schooling, fertility is independent of $x$ as well. ¿From equations (3) and (5) we see that parents choosing private education have a lower fertility rate.

\section{Lemma 1 (Constant parental spending on children)}

For given $s, v$ and $x$, parental spending on children (and therefore taxable income) does not depend on the choice of private versus public schooling, and is equal to $\frac{\gamma}{1+\gamma} x$.

Lemma 1 implies that the tax base does not depend on the fraction of people participating in public schooling. This property will be important for generating 
uniqueness of equilibrium. The lemma relies on three assumptions: homothetic preferences, tax deductible education spending, and endogenous fertility. With endogenous fertility, parents choosing private schools have fewer children, keeping their total budget allocation to children in line with those choosing public schools. ${ }^{9}$ This is a typical feature of endogenous fertility models.

A first result is that parents with high human capital are more demanding in terms of expected public education quality, or, in other words, child quality is a normal good:

\section{Lemma 2 (Opting out decision)}

There exist an income threshold:

$$
\tilde{x}=\frac{1-\eta}{\delta \phi \eta} E[s] \quad \text { with: } \delta=(1-\eta)^{\frac{1}{\eta}}
$$

such that households strictly prefer private education if and only if $x>\tilde{x}$.

Here $E[s]$ is expected quality of public schooling. An implication of the above lemma is that if some people with income $x$ choose the public regime, all people with income $x^{\prime}<x$ will strictly prefer public schooling. Similarly, if at least some people with income $x$ opt out of public education and choose private education, all households with income $x^{\prime}>x$ choose it as well.

We assume a uniform distribution of human capital over the interval $[1-\sigma, 1+$ $\sigma]$. Accordingly, the associated density function is given by $g(x)=0$ for $x<1-\sigma$ and if $x>1+\sigma$, and $g(x)=1 /(2 \sigma)$ for $1-\sigma \leq x \leq 1+\sigma \cdot{ }^{10}$ We denote the

\footnotetext{
${ }^{9}$ With fixed fertility, the resources allocated to children would be $x \phi n$ with public education and $x \phi n /(1-\eta)$ with private education. However, even with fixed fertility a constant tax base could be achieved through an endogenous labor supply setup.

${ }^{10}$ The uniform distribution of human capital is chosen for simplicity; other distributions would lead to similar results. In particular, in the probabilistic voting model described below (unlike the standard majority voting model) there is no special significance to the relative positions of median and mean income.
} 
fraction of children participating in the public education system as:

$$
\Psi=\left\{\begin{array}{lll}
0 & \text { if } & \tilde{x}<1-\sigma, \\
\frac{\tilde{x}-(1-\sigma)}{2 \sigma} & \text { if } & 1-\sigma \leq \tilde{x} \leq 1+\sigma, \\
1 & \text { if } & \tilde{x}>1+\sigma .
\end{array}\right.
$$

\subsection{The political mechanism}

The public education system operates under a balanced-budget rule:

$$
\begin{aligned}
& \int_{0}^{\tilde{x}} n^{s} s g[x] d x= \\
& \quad \int_{0}^{\tilde{x}} v\left(x\left(1-\phi n^{s}\right)\right) g[x] d x+\int_{\tilde{x}}^{\infty} v\left(x\left(1-\phi n^{e}\right)-e[x] n^{e}\right) g[x] d x,
\end{aligned}
$$

with total spending on public education on the left-hand side and total revenues on the right-hand side. After replacing fertility and education by their optimal value, this constraint reduces to:

$$
v=\Psi \frac{\gamma}{\phi} s
$$

Since the level of schooling and taxes are linked through the budget constraint, the policy choice is one-dimensional.

The level of public expenditures, and hence taxes, is chosen through probabilistic voting. Assume that there are two political parties, $p$ and $q$. Each one proposes a policy $s^{p}$ and $s^{q}$. The utility gain (or loss) of a voter with income $x$ if party $q$ wins the election instead of $p$ is $u\left[x, v^{q}, n, e, s^{q}\right]-u\left[x, v^{p}, n, e, s^{p}\right]$. Instead of assuming that an adult votes for party $q$ with probability one every time this difference is positive (as in the median voter model), probabilistic voting theory supposes that this vote is uncertain. More precisely, the probability that a person votes for party $q$ is given by

$$
F\left(u\left[x, v^{q}, n, e, s^{q}\right]-u\left[x, v^{p}, n, e, s^{p}\right]\right),
$$


where $F$ is an increasing and differentiable cumulative distribution function. This function captures the idea that voters care about an "ideology" variable in addition to the specific policy measure at hand, i.e., the quality of public schooling. The presence of a concern for ideology, which is independent of the policy measure, makes the political choice less predictable (see Persson and Tabellini 2000 for different formalizations of this approach). The probability that a given voter will vote for party $q$ increases gradually as the party's platform becomes more attractive. Under standard majority voting, in contrast, the probability of getting the vote jumps discretely from zero to one once party $q$ offers a more attractive platform that party $p$.

Since the vote share of each party varies continuously with the proposed policy platform, probabilistic voting leads to smooth aggregation of all voters' preferences, instead of depending solely on the preferences of the median voter. Party $q$ maximizes its expected vote share, which is given by $\int_{0}^{\infty} g[x] F(\cdot) d x$. Party $p$ acts symmetrically, and, in equilibrium, we have $s=s^{q}=s^{p}$. The maximization program of each party implements the maximum of the following weighted social welfare function: ${ }^{11}$

$$
\int_{0}^{\infty} g[x](F)^{\prime}(0) u[x, v, n, e, s] d x .
$$

The weight $(F)^{\prime}(0)$ captures the responsiveness of voters to the change in utility. If there are different groups in the population that differ in their responsiveness (their "ideological bias"), the distribution of political power becomes uneven. In particular, a group that has little ideological bias cares relatively more about economic policy. Such groups are therefore targeted by politicians and enjoy high political power. In addition, political power may also depend on other features of the political system such as voting rights. We will capture the political power of each person by a single parameter $\theta[x]$. This includes the extreme cases of representative democracy with equal responsiveness, and dictatorship of the rich $(\theta[x]=0$ for $x$ below a certain threshold). Accordingly, the objective function

\footnotetext{
${ }^{11}$ This result was first derived by Coughlin and Nitzan (1981). The same framework can also be derived within the setup of lobbying models, see Bernheim and Whinston (1986).
} 
maximized by the probabilistic voting mechanism is given by:

$$
\Omega[s] \equiv \int_{0}^{\tilde{x}} u\left[x, v, n^{s}, 0, s\right] \theta[x] g[x] d x+\int_{\tilde{x}}^{\infty} u\left[x, v, n^{e}, e[x], 0\right] \theta[x] g[x] d x
$$

The maximization is subject to the government budget constraint (8).

We start by assuming that all individuals have the same political power, i.e. $\theta[x]=1$, implying that the weight of a given group in the objective function is simply given by its size. The role of this assumption will be further investigated in Section 4 . It can be checked that $\Omega[s]$ is strictly concave. Replacing $\tilde{x}$ by $2 \sigma \Psi+1-\sigma$ into the objective, taking the first-order condition for a maximum, and solving for $s$ yields:

$$
s=\frac{\eta \phi}{1+\gamma \eta \Psi} \equiv s[\Psi]
$$

From this expression we can see that $s$ is decreasing in the participation rate $\Psi$ : when more children participate in public schools, spending per child is reduced. Looking at the corresponding tax rate,

$$
v=\frac{\eta \gamma \Psi}{1+\gamma \eta \Psi}
$$

we observe that a rise in participation is followed by a less than proportional rise in taxation. Since, by Lemma 1 , the taxable income is unaffected by increased participation, this translates into lower spending per child. To see the intuition for this result, consider the consequences of increasing $\Psi$ for a given $s$. In the welfare function maximized by the political system, the increase in $\Psi$ leads to a proportional increase in the marginal benefit of increasing schooling $s$, since more children benefit from public education. The marginal cost of taxation, in contrast, increases more than proportionally, since the higher required taxes reduce consumption and increase marginal utilities. To equate marginal costs and benefits, an increase in $\Psi$ is therefore met by a reduction in $s$. 

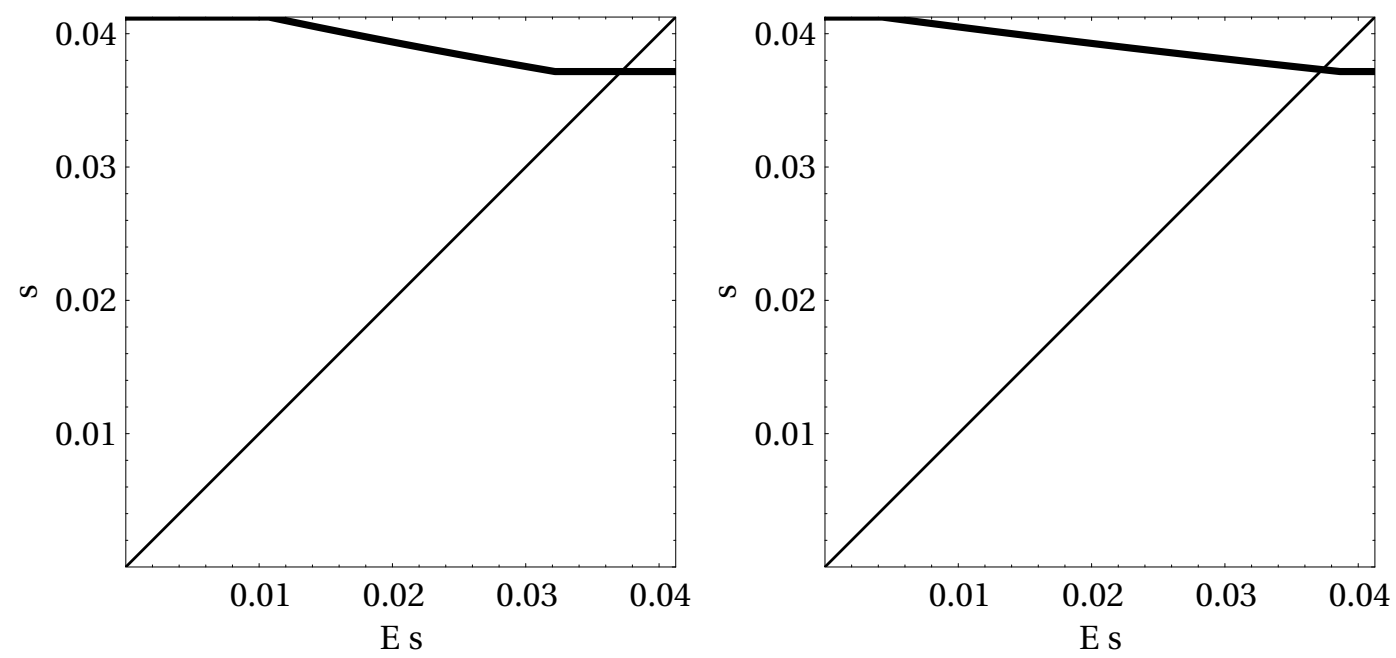

Figure 1: The fixed point with $\sigma=0.5$ (left) and $\sigma=0.8$ (right)

\subsection{The equilibrium}

So far, we have taken the participation rate $\Psi$ as given, and solved for the corresponding voting outcome concerning the quality of public schools. In equilibrium, the choice whether or not to participate in public schooling has to be optimal. In the definition of equilibrium we will use an earlier result: the incentive to use private schooling is increasing in income (Lemma 2). As a consequence, any equilibrium is characterized by an income threshold $\tilde{x}$ such that people choose public education below $\tilde{x}$ and private education above $\tilde{x}$. This leads to the following definition of an equilibrium:

\section{Definition 1 (Equilibrium)}

An equilibrium consists of an income threshold $\tilde{x}$ satisfying (6), a fertility rule $n=n^{s}$ for $x \leq \tilde{x}$ and $n=n^{e}$ for $x>\tilde{x}$, a private education decision $e=0$ for $x \leq \tilde{x}$ and $e=e[x]$ for $x>\tilde{x}$, and aggregate variables $(\Psi, s, v)$ given by equations (7), (11) and (12), such that the perfect foresight condition holds:

$$
E[s]=s .
$$

\section{Proposition 1 (Existence and Uniqueness of Equilibrium)}

An equilibrium exists and is unique. 
To see the intuition for the result, notice that participation in public schooling is a continuously increasing function of expected school quality through equations (7) and (6). Actual school quality, in turn, is a continuous and decreasing function of participation. Combining these results, we can construct a continuous and decreasing mapping from expected to actual school quality. This mapping has a unique fixed point, which characterizes the equilibrium.

The uniqueness result relies on endogenous fertility. If one assumes, to the contrary, that fertility is exogenous and constant, Lemma 1 no longer holds, and the tax basis increases with participation $\Psi$. If the tax-basis effect is sufficiently pronounced, the actual schooling level will no longer decrease in participation, and the equilibrium mapping may fail to have a unique fixed point.

Figure 1 shows two numerical examples of the fixed point mapping. The chosen parameters are: $\gamma=0.4, \eta=0.55, \phi=0.075$. The implied fertility levels are $n^{e}=1, n^{s}=2.22$. In the left panel, $\sigma=0.5$, and we have $s=0.034$ and $\Psi=1$. In the right panel, $\sigma=0.8$, and we have $s=0.037$ and $\Psi=0.96$.

\section{Comparing the Education Regimes}

Depending on the coverage of the public education system, we have three cases to consider.

\begin{tabular}{lc}
\hline \hline Regime & $\Psi$ \\
\hline Fully Public & 1 \\
Segregation & $\in(0,1)$ \\
Fully Private & 0 \\
\hline
\end{tabular}

In the fully public regime, all children go to public school. Under segregation, the most skilled parents send their children to private school, while others use public schools. In the fully private regime, everybody attends private schools. We first derive the conditions under which each education regime arises. The following proposition summarizes the results. 


\section{Proposition 2 (Occurrence of education regimes)}

The fully private regime is not an equilibrium outcome.

Whether public schooling can arise in equilibrium depends on the preference parameters $\gamma$ and $\eta$. Let $\hat{\gamma}=(1-\delta-\eta) /(\delta \eta)$.

If $\gamma>\hat{\gamma}$, public education is not an equilibrium outcome and $\Psi<1 / 2$ for any $\sigma$.

If $\gamma<\hat{\gamma}$, the fully public regime prevails if and only if

$$
\sigma \leq \hat{\sigma}=\frac{1-\eta}{(1+\gamma \eta) \delta}-1 .
$$

Otherwise, we have segregation with $\Psi>1 / 2$.

Let us first explain why the fully private regime cannot be an equilibrium outcome. When participation is very low $(\Psi \rightarrow 0)$, high quality public education can be provided at very low tax levels. The quality of public schools is then sufficiently high $(s \rightarrow \eta \phi)$ for the poorest parents to prefer public over private education.

To see whether a fully public regime can arise, we have to look at the preferences of the richest person. If this person has a high income relative to the average (high $\sigma$ ), the preferred education quality is sufficiently larger than publicly provided schooling for private education to be optimal. The effect of inequality on segregation is established in the next proposition. The fully public regime arises only if the income distribution is sufficiently compressed, so that the preferred education level varies little in the population. From now on we restrict attention to the region of the parameter space where the fully public regime can occur for a sufficiently compressed income distribution, and where at any time at least half the population is in public schools.

Assumption 1 The model parameters satisfy:

$$
\gamma<\hat{\gamma} \equiv \frac{1-\delta-\eta}{\delta \eta}
$$


As in nearly all countries participation in public schools far exceeds 50 percent, this is the empirically relevant case. ${ }^{12}$

Proposition 3 (Inequality and segregation) Under Assumption 1, an increase in inequality leads to a lower share of public schooling, a higher quality of public schooling, and lower taxes:

$$
\frac{\partial \Psi}{\partial \sigma} \leq 0, \frac{\partial s}{\partial \sigma} \geq 0, \frac{\partial v}{\partial \sigma} \leq 0 .
$$

The inequalities are strict if a positive fraction of parents already uses private schools.

Higher income inequality leads to lower participation in public schools and more segregation ( $\Psi$ closer to $1 / 2$ ) if the majority of the population is in public schools. Intuitively, in this case an increase in inequality raises the income of the marginal person (who was just indifferent between private and public schooling before the increase in inequality). As a consequence, the preferred level of education increases, and this person now strictly prefers private schooling. The lower participation in public schooling after an increase in inequality also implies that the tax rate goes down. Thus, despite the increased demand for redistribution, everybody is taxed less as more parents opt out of the public schooling system.

The preferences of households at the income threshold $\tilde{x}$ are linked to the relative quality of public versus private schooling. At the threshold, households are indifferent between both types of schools. This implies that the quality they receive from public schools is lower than the one from private schools, since the gap between the two has to compensate for higher costs of private education. This result is consistent with the literature devoted to the estimation of the relative quality of private education, correcting for the effect of higher social class of the pupils in the private sector. The majority of the results suggest that controlling for sample selectivity reduces the achievement advantage of private school students over public school students, but does not eliminate it. ${ }^{13}$

\footnotetext{
${ }^{12}$ Put differently, using the calibrated parameter values $\eta=0.6$ and $\phi=0.075$ from de la Croix and Doepke (2003a), Assumption 1 can be read as a condition on fertility $n^{s}$ (see Equation (3)). The condition imposes $n^{s}<7.79$ per person, which requires fertility per woman to be smaller than 15.6 children.

${ }^{13}$ See Kingdon (1996) for India, Bedi and Garg (2000) for Indonesia, Alderman, Orazem, and Paterno (2001) for Pakistan, Vandenberghe and Robin (2003) for Brazil and Neal (1997) for Catholic U.S. schools. Some other studies find no difference between private and public schools performances (see Goldhaber (1996)).
} 
Notice that if Assumption 1 is satisfied, the unique equilibrium in a economy without inequality $(\sigma=0)$ is fully public schooling. The result may seem surprising at first sight, because public schooling implies a fiscal externality. In an equitable society, the social optimum would be pure private schooling. The reason why public schooling arises nevertheless is linked to our timing assumptions. If parents commit to a schooling choice before the schooling quality is set, a holdup problem arises. From an ex ante perspective, it would be socially optimal for everybody to commit to using private schools. Ex post, however, if some parents decide to go for public schools anyway, the political system will provide a quality of public schooling that makes this decision optimal after the fact. Thus, the expectation that a certain public service will be provided creates a constituency that ensures that the service will be provided in reality.

\section{Political Power and Multiple Equilibria}

In this section, we relax the earlier assumption that each member of the population carries equal weight in the voting process. We will see that if political power is concentrated among high-income individuals, multiple equilibria can arise.

As a particularly simple form of variable political power, we consider outcomes with a minimum-income restriction for voting. There is now a threshold $\bar{x}$ such that only individuals with income $x \geq \bar{x}$ are allowed to vote. ${ }^{14}$ All individuals above the threshold continue to carry equal weight in the voting process. This formulation captures property restrictions on voting, which were common in the early phases of many democracies. Similar cases of political exclusion can also arise from literacy requirements, age restrictions on voting (given that young people tend to be relatively poor), citizenship restrictions (assuming that recent immigrants are poorer on average than the native population), and political mechanisms other than voting (such as lobbying and bribery) that favor the rich in either democracies on non-democracies.

\footnotetext{
${ }^{14}$ Similar results would obtain if individuals below the threshold had positive, but sufficiently low weight in the political mechanism.
} 
The objective function of the political system is now given by:

$$
\Omega[s] \equiv \quad \int_{\bar{x}}^{\max \{\bar{x}, \tilde{x}\}} u\left[x, v, n^{s}, 0, s\right] g[x] d x+\int_{\max \{\bar{x}, \tilde{x}\}}^{\infty} u\left[x, v, n^{e}, e[x], 0\right] g[x] d x .
$$

Replacing $\tilde{x}$ by $2 \sigma \Psi+1-\sigma$ into the objective, taking the first-order condition for a maximum, and solving for $s$ yields:

$$
\text { If } \Psi \geq \frac{\bar{x}-(1-\sigma)}{2 \sigma}, \quad \begin{aligned}
\quad & =\frac{\eta \phi((1-\sigma)-\bar{x}+2 \sigma \Psi)}{\Psi(\gamma \eta((1-\sigma)-\bar{x}+2 \sigma \Psi)+(1+\sigma)-\bar{x})} . \\
\text { If } \Psi & <\frac{\bar{x}-(1-\sigma)}{2 \sigma}, \quad s=0 .
\end{aligned}
$$

Hence, with a biased political system corner solutions with a schooling quality of zero may arise. The equilibrium schooling quality $s$ satisfies:

$$
s=\max \left\{\frac{\eta \phi(1-\sigma-\bar{x}+2 \sigma \Psi)}{\Psi(1+\sigma-\bar{x}+\gamma \eta(1-\sigma-\bar{x}+2 \sigma \Psi))}, 0\right\} .
$$

The corresponding tax rate is still given by (12). A few properties of (16) are of interest here. First, we have $s=0$ for $\Psi \leq \bar{x}-(1-\sigma) / 2 \sigma$. Second, we have:

$$
s=\max \left\{\frac{\eta \phi}{\frac{(1+\sigma-\bar{x}) \Psi}{(1-\sigma-\bar{x}+2 \sigma \Psi)}+\gamma \eta \Psi}, 0\right\} \leq \frac{\eta \phi}{1+\gamma \eta \Psi},
$$

where the right-hand side is the schooling level that arises with equal political power as given by (11). Finally, for $\Psi=1$ we have

$$
s=\frac{\eta \phi}{1+\gamma \eta}
$$

just as in the case with equal political power. In the new formulation with variable voting power, the existence of equilibrium can still be proven. However, the equilibrium is no longer necessarily unique. It is also no longer true that the fully private regime never exists (as we showed in Proposition 2 for the democratic case of an even distribution of political power). In fact, in the biased political 


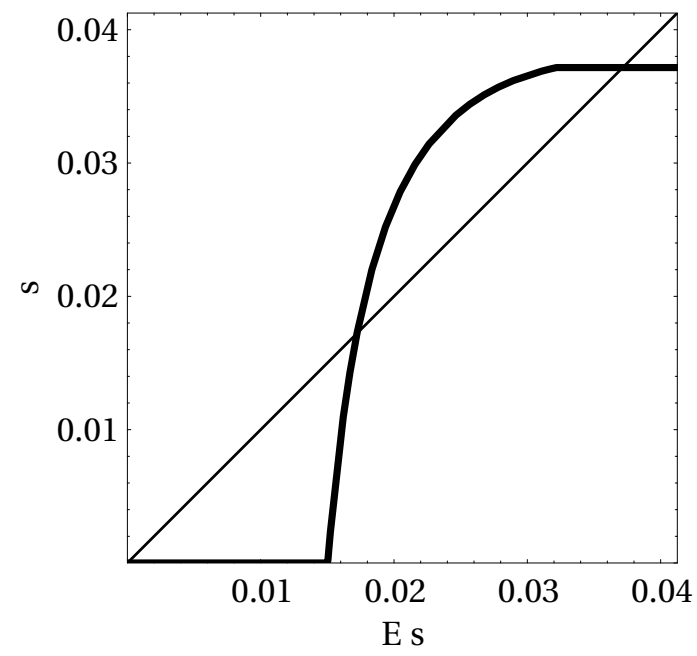

Figure 2: The fixed point with multiple equilibria $(\sigma=0.5, \bar{x}=0.7)$

system pure private schooling is always an equilibrium outcome.

As soon as $\tilde{x}$ is smaller than $\bar{x}$, i.e., all voters expect to send their children to private schools, the chosen school quality is zero. Intuitively, these voters care only about taxes, but not about the quality of public schools that they do not use. As a consequence, private schooling becomes attractive to all parents.

To show that multiple equilibria can arise, we concentrate on the parameter space where fully public schooling is the unique equilibrium when $\bar{x}=0$. We establish that in this case there are at least three equilibria for $\bar{x}>1-\sigma$.

\section{Proposition 4 (Multiplicity of equilibria for $\bar{x}>1-\sigma$ )}

If $\bar{x}, \gamma$, and $\sigma$ satisfy the conditions

$$
\bar{x}>1-\sigma, \quad \gamma<\hat{\gamma}, \quad \text { and } \quad \sigma \leq \hat{\sigma}=\frac{1-\eta}{(1+\gamma \eta) \delta}-1,
$$

there are at least three equilibria. One is a fully private regime, one a fully public regime, and one features segregation.

In Figure 2 we take the same parameter values as in Figure 1 and we set $\sigma=0.5$ and $\bar{x}=0.7$, which implies that the bottom $20 \%$ have no political power. There 
are now three fixed points: $s=0, s=0.017$, and $s=0.037$, with participation $\Psi=0, \Psi=0.3$, and $\Psi=1$.

The possibility of multiple equilibria exists because we assume that people have to decide on fertility and public versus private schooling before the vote on the quality of public education takes place. If all decisions were taken simultaneously, the voting process would lead to the same outcome as the weighted social planning problem, which is generically unique. Pre-commitment generates multiplicity in this setting, but not in the version with equal political weights, because there is now a strategic complementarity between the education choices of skilled people through the quality of public schools. ${ }^{15}$ When everybody with political power uses private schools, an given individual does not want to switch to the public system, since the quality of the public schooling is low. If, however, all voters were to switch together to the public system, they would vote for a much higher quality of public schools; in that case it would be rational to stay in the public system. Here, the political bias towards the rich offsets the increased cost of taxation resulting from higher participation in public schooling. Provided that there is a strong concentration of political power, the model can account for the fact that some countries with similar general characteristics choose very different educational systems. ${ }^{16}$

The next proposition shows that despite the possibility of multiple equilibria, the coverage of public schooling is never higher in societies dominated by the rich than in democracies:

\section{Proposition 5 (Coverage of public education as a function of $\bar{x}$ )}

\footnotetext{
${ }^{15}$ When actions are strategic complements, the utility of those taking the action depends positively on how many people take the action. Classic examples are Matsuyama (1991) for increasing returns, Katz and Shapiro (1985) for network externalities, and Diamond and Dybvig (1983) for bank runs.

${ }^{16} \mathrm{~A}$ number of authors have derived similar multiplicity results in other applications of voting models. In Saint-Paul and Verdier (1997) there is majority voting on a capital income tax. If political power is unequally distributed, and is biased in favor of households having better access to world capital markets, expectations-driven multiple equilibria can arise. In a dynamic majority voting framework, Hassler, Rodriguez Mora, Storesletten, and Zilibotti (2003) assume that young agents base their education decisions on expectations over future redistribution. Self-fulfilling expectations can lead to either high or low redistribution equilibria. Finally, there are other political economy models that do not have indeterminacy of equilibrium but display multiple steady states (see for example Bénabou 2000 or Doepke and Zilibotti 2005). Initial conditions, as opposed to self-fulfilling expectations, determine which steady state the economy approaches.
} 
Let $\Psi_{0}$ be the equilibrium coverage of public education for $\hat{x}=x_{0}$, and $v_{0}$ the corresponding tax rate. If $\Psi_{1}$ and $v_{1}$ are an equilibrium coverage and a tax rate for a $\hat{x}=x_{1}>x_{0}$, then we have

$$
\begin{aligned}
\Psi_{1} & \leq \Psi_{0} \\
s_{1} & \leq s_{0} \\
v_{1} & \leq v_{0} .
\end{aligned}
$$

In summary, if the rich wield more power than the poor, multiple equilibria may arise. In any such equilibrium, the coverage and quality of and spending on public education cannot be higher than in the outcome with equal political weights. Fully private education systems are always possible.

While we have established the results of this section for the extreme case where households with an income below $\bar{x}$ do not wield any political power, the results generalize to an environment where these households have some positive weight in the political system, but lower than the weight of households with income above $\bar{x}$. In particular, it is easy to establish that, for any $\bar{x}$, a fully private regime exists if the weight of low-income people is sufficiently small. As before, if in this case the unique equilibrium in the model with an even distribution of political power is pure public schooling, at least three equilibria exist when the poor have less political power.

\section{Outcomes with Government Commitment}

So far we have assumed that the level of government spending on education is determined after private households have decided whether to send their children to private or public schools. In this section we analyze an alternative timing assumption, namely, the voters elect a government which pre-commits to a given overall spending level on education, while households can make their schooling choice conditional on this spending. Even though under each timing assumption people have perfect foresight, we will see that timing makes an important difference. For the following analysis, we return to the assumption of an even 
distribution of political power, i.e. $\bar{x}=0$.

In the new timing, the government sets the tax rate at the beginning of the period. Since the tax base is independent of the schooling choice, this is equivalent to determining total spending on public education. After the tax is set, parents choose fertility and public versus private education for their children. Public schooling per child will then be simply given by the ratio of pre-committed total spending to the number of children in public schools. Since the government has perfect foresight, the problem can be solved backwards by first determining individual decisions as a function of policies, and then choosing policies taking this dependency into account.

Since fertility choices conditional on schooling are not affected by taxes, fertility rates will be as before determined by equations (3) and (5). Private education spending is also unaffected by the new timing of decisions and is given by equation (4). The participation decision is determined by the threshold defined in Lemma 2, which is now defined in terms of actual schooling quality s:

$$
\tilde{x}[s]=\frac{1-\eta}{\delta \phi \eta} s
$$

We also redefine the endogenous fraction of children participating in the public education system as a function of actual quality:

$$
\Psi[s]=\left\{\begin{array}{lll}
0 & \text { if } & \tilde{x}[s]<1-\sigma \\
\frac{\tilde{x}[s]-(1-\sigma)}{2 \sigma} & \text { if } & 1-\sigma \leq \tilde{x}[s] \leq 1+\sigma \\
1 & \text { if } & \tilde{x}[s]>1+\sigma
\end{array}\right.
$$

From Equation (9), the link between taxes and expenditures is given by:

$$
v=\Psi[s] \frac{\gamma}{\phi} s
$$

The objective function modeling the voting process is the same as before, but $\Psi$ 
and $\tilde{x}$ are now endogenous:

$$
\Omega[s] \equiv \int_{0}^{\tilde{x}[s]} u\left[x, v, n^{s}, 0, s\right] g[x] d x+\int_{\tilde{x}[s]}^{\infty} u\left[x, v, n^{e}, e[x], 0\right] g[x] d x .
$$

The structure of the problem is similar to a standard Ramsey (1927) problem, where the government chooses optimal taxes taking into account the reaction of private agents. Once again three regimes are possible: fully public $(\Psi[s]=1)$, segregation $(1>\Psi[s]>0)$, and fully private $(\Psi[s]=0)$. In the segregation case, the first-order condition for optimization is as follows:

$$
\begin{aligned}
\int_{0}^{\tilde{x}[s]}\left(\frac{\partial u}{\partial v} \frac{\partial v}{\partial s}+\frac{\partial u}{\partial s}\right) g[x] & d x+\int_{\tilde{x}[s]}^{\infty}\left(\frac{\partial u}{\partial v} \frac{\partial v}{\partial s}+\frac{\partial u}{\partial s}\right) g[x] d x \\
+ & \int_{0}^{\tilde{x}[s]} \frac{\partial u}{\partial v} \frac{\partial v}{\partial \Psi} \frac{\partial \Psi}{\partial s} g[x] d x+\int_{\tilde{x}[s]}^{\infty} \frac{\partial u}{\partial v} \frac{\partial v}{\partial \Psi} \frac{\partial \Psi}{\partial s} g[x] d x=0 .
\end{aligned}
$$

The first line of this optimality condition is the same as the one we get in the problem without commitment. The second line is a new term which arises from the endogenous dependency of $\Psi$ on $s$. This term is always negative. The new negative term implies that under government commitment, the optimal $s$ is lower than under no-commitment, as long as the solution for $\Psi$ is interior. Intuitively, the government now takes into account that a marginal increase in $s$ increases the number of families who use public schools. On the margin this lowers the value of the objective function, since the marginal family is just indifferent between private and public schooling, but imposes a fiscal burden on the rest of the population once it switches from private to public school.

In the fully private and public regimes, participation $\Psi[s]$ is locally independent of $s$, as long as the marginal family strictly prefers its current schooling choice. The additional term is therefore zero, and hence the optimal schooling choice of $s$ does not depend on government commitment. The following proposition summarizes the result.

\section{Proposition 6 (Equilibrium with commitment)}

An equilibrium with commitment exists. Public school quality is lower than or equal to the level reached without commitment. The inequality is strict if participation $\Psi$ satisfies: 
$0<\Psi<1$.

Existence is guaranteed because the objective function is continuous on a compact set. The equilibrium is not guaranteed to be unique, however, because the objective function is not globally concave. In particular, it has kinks at the values of $s$ corresponding to $\tilde{x}[s]=1-\sigma$ and $\tilde{x}[s]=1+\sigma$. However, multiplicity occurs only for knife-edge cases.

If we extend this model to concentrated political power as in Section 4, we no longer get generic multiplicity of equilibria. Under the original timing, multiple equilibria arose as self-fulfilling prophecies. With government commitment, the government moves first and chooses the generically unique equilibrium that maximizes the objective function.

To summarize, we see that the relative timing of the decisions taken by individual households and the government has an important bearing on the positive implications of our theory. Which timing, then, should be considered to be the most realistic? Clearly, there is no general answer to this question, as political decision horizons can vary substantially from country to country. It is useful, however, to consider as a benchmark the common case of a government that adjusts the education budget (which determines the quality of public schooling) at an annual frequency. As far as fertility decisions are concerned, the realistic assumption then is that households move before the government. Children generally enter school at age six, so that at the very minimum, six years pass from the fertility decision until schooling actually begins. It is hard to imagine that the government commits to a schooling quality more than six years ahead of time, without any possibility of later adjustments.

In contrast, matters are less clear-cut when it comes to the choice of an education system (i.e., whether to send one's child to public or private school). We have already analyzed the case where parents make this choice before the government decides on school quality. What would happen if households chose fertility before the vote on schooling quality, but could adjust their choice of public versus private schooling after the vote? As we will see, this framework in which households make at least one decision before the government leads to similar implications as our original timing where the government moves last. 
In this intermediate case, when households choose fertility, they do so under perfect foresight regarding the future quality of schools. There will be an income threshold $\bar{x}$ below which people have large families (corresponding to the expectation of public schooling). The objective of the voting process takes three different forms depending on how the threshold for private education $\tilde{x}[s]$ compares to the threshold for small families $\bar{x}$. For $\bar{x}<\tilde{x}[s]$, it is given by:

$$
\begin{aligned}
& \Omega[s]=\int_{0}^{\bar{x}} u\left[x, v, n^{s}, 0, s\right] g[x] d x+\int_{\bar{x}}^{\tilde{x}[s]} u\left[x, v, n^{e}, 0, s\right] g[x] d x \\
&+\int_{\tilde{x}[s]}^{\infty} u\left[x, v, n^{e}, e[x], 0\right] g[x] d x,
\end{aligned}
$$

for $\bar{x}=\tilde{x}[s]$, we have

$$
\Omega[s]=\int_{0}^{\tilde{x}[s]} u\left[x, v, n^{s}, 0, s\right] g[x] d x+\int_{\tilde{x}[s]}^{\infty} u\left[x, v, n^{e}, e[x], 0\right] g[x] d x,
$$

and for $\bar{x}>\tilde{x}[s]$, we have:

$$
\begin{aligned}
\Omega[s]=\int_{0}^{\tilde{x}[s]} u\left[x, v, n^{s}, 0, s\right] g[x] d x+\int_{\tilde{x}[s]}^{\bar{x}} u\left[x, v, n^{s}, e[x], 0\right] g[x] d x \\
\\
+\int_{\bar{x}}^{\infty} u\left[x, v, n^{e}, e[x], 0\right] g[x] d x .
\end{aligned}
$$

If $\bar{x} \neq \tilde{x}[s]$, as in the previous case the first-order condition for optimality has an additional term related to the marginal impact of $s$ on $\tilde{x}[s]$. In equilibrium, however, agents have perfect foresight, and $\bar{x}=\tilde{x}[s]$ will hold. In this case, consider the $s$ that maximizes the objective function holding $\tilde{x}[s]$ constant at $\bar{x}$, as in our original timing. In Equation (21), in a neighborhood around this $s$, it is the case that the marginal effect of a change in $s$ on $\tilde{x}$ is zero. The reason is that agents below $\bar{x}$ have chosen large families in expectation of using public schools, whereas families above $\bar{x}=\tilde{x}[s]$ have chosen small families in expectation of private schooling. Families close to the threshold therefore strictly prefer their expected schooling choice to the alternative. Thus for $\bar{x}=\tilde{x}[s]$ which occurs in equilibrium, the first-order condition is as in our original timing. If the solution 
is interior, this implies that the outcome has to be the same. ${ }^{17}$

To summarize, whether the model generates multiplicity of equilibria crucially depends on the timing of private decisions relative to the determination of government policy. If parents make decisions that lock them into specific choices for their children for a long time, whereas the government can adjust the quality of public education more frequently, the possibility of multiple equilibria is present. In the real world, the strength of these lock-in effects would depend on a number of features that are not explicitly modeled in our theory. For example, in some countries educational segregation is linked to residential segregation, i.e., there are some districts where mostly rich people live who use private schools, whereas poorer districts are served by public schools. In such an environment, a switch in the type of schooling would also entail a switch of residence, and maybe even a switch of jobs if the distances are sufficiently large. Clearly, in such an environment the lock-in into a particular schooling type would be much stronger than in a country where private and public schools exist right next to each other, with few hurdles to switching schools.

\section{Empirical Evidence}

Our theory makes predictions on how the quality and extent of private and public schooling are determined at the aggregate level, and on how schooling and fertility choices vary across households within a given political entity. In this section, we compare these predictions to data. We start by focusing on state-level variation in the extent and quality of public education in the United States. This setting is well suited to examine the predictions of our theory for democratic countries, as all U.S. states operate within the same overall political framework, while exhibiting considerable variation in schooling policies as well as the distribution of income. Moreover, we are able to link state-level evidence to household data from the U.S. Census to assess the micro implications of our theory. We then

\footnotetext{
${ }^{17}$ Depending on parameters, however, under the intermediate timing there can also be additional corner solutions. The original and intermediate timing lead to the same equilibria if the lock-in effect through fertility is sufficiently strong. The strength of the lock-in effect, in turn, depends on the fertility differential between parents with children in public and private schools.
} 
extend the analysis to cross-country data, which allows us to probe the theory's predictions for non-democratic countries. Here we use data from the OECD and the World Bank on public and private education spending, as well as micro data from the OECD Programme for International Student Assessment (PISA).

\subsection{Inequality, fertility, and schooling across U.S. states}

Our model predicts that in a democracy, the choice of public versus private schooling as well as the level of funding of public schooling are driven by income inequality (see Proposition 3). In particular, a state with higher income inequality should exhibit a higher share of private schooling, lower overall spending on public schooling, but higher public education spending per student. In addition, the model predicts that a high-inequality state will have a relatively low fertility rate, because parents who send their children to private school economize on fertility. In this section, we examine whether these predictions hold up across U.S. states.

We computed state-level measures of income inequality, average fertility, and the share of private schooling from the 2000 U.S. Census. ${ }^{18}$ We correlate these variables with a number of measures of the spending on and the quality of public schooling. In line with the setup of our theory, we focus on financial measures. ${ }^{19}$ As an overall spending measure, we use public education spending per capita in each state (this corresponds to the tax rate $v$ in the model). For the quality of public education (corresponding to the variable $s$ in the model), we consider three alternative measures. "Total Current Expenditure per Student" is a measure of total spending for day-to-day operation of schools, which includes all expenditures of public schools apart from debt repayments, capital outlays, and programs outside of preschool to grade 12 . One concern with this broad measure is that it includes some items that may not have a direct educational impact. We therefore also use the variable "Total Instruction Expenditure per Student,"

\footnotetext{
${ }^{18}$ The data is from the one-percent sample of the 2000 U.S. Census, made available at www.ipums.org by Ruggles et al. (2004).

${ }^{19}$ There may also be differences in how efficiently a given amount of spending is converted into "effective education," but our theory makes no predictions in this dimension and assumes that all states are at the efficiency frontier.
} 
Table 1: Correlation of Inequality and Share of Private Schooling with Fertility, Education Spending, and the Quality of Public Schooling across U.S. States

\begin{tabular}{lcc}
\hline \hline & Gini coefficient & Private school share \\
\hline Private school share & $0.36(2.65)$ & \\
Public spending per capita & $-0.45(-3.51)$ & $-0.08(-0.58)$ \\
Public spending per student & $0.26(1.84)$ & $0.55(4.57)$ \\
Public instruction spending per student & $0.18(1.23)$ & $0.53(4.34)$ \\
Mean teacher salary in public schools & $0.25(1.77)$ & $0.61(5.33)$ \\
Average number of children & $-0.48(-3.74)$ & $-0.27(-1.91)$ \\
\hline
\end{tabular}

t-Statistics in parentheses. "Gini Coefficient" is computed on 1999 household income by state (data from 2000 U.S. Census). "Share in Private School" is the number of households with at least half of their school-age children in private school as a fraction of the total number of households with at least one child in school (data from 2000 U.S. Census). "Number of Children" is the average number of children per household in the same data set, where children are counted only if the head of household is their parent and if they are currently living in the household. Measures of education spending and quality of education are defined in the text.

which only includes expenditures directly associated with student-teacher interaction such as teacher salaries and benefits, textbooks and other teaching supplies, and purchased instructional services. Finally, as an alternative measure of the quality of instruction we use "Mean Teacher Salary," an estimate of the average annual salary of teachers in public elementary and secondary schools. ${ }^{20}$

Table 1 shows how income inequality (i.e., the Gini coefficient on household income by state) and the share of private schooling correlate with fertility and measures of education spending and quality across states. The correlations are in line with the predictions of Proposition 3. In particular, the correlation between inequality and the share of private schooling is positive, whereas the correlation between inequality and per-capita spending on public education is negative. Taken by themselves, these results might seem to suggest that more inequality leads

\footnotetext{
${ }^{20}$ The expenditure measures are from the National Center for Education Statistics, "Revenues and Expenditures for Public Elementary and Secondary Education," School Year 2000-2001. The teacher salary data is provided by the National Education Association.
} 
to less redistribution in the sense of lower support for public education. However, this is not in fact the case when we consider the quality of public education rather than overall spending. All three measures of the quality of public education are positively correlated with inequality. ${ }^{21}$ This verifies the third part of Proposition 3.

The surprising finding that the correlation coefficients of education spending per capita and education spending per student are of opposite sign can be accounted for by the effect of private schooling on the quality of public schooling. As inequality rises, more students use private schools, which makes it more affordable to offer a high-quality education to those still in public schools. This effect can be seen even more strongly when we correlate education quality with the share of students in private school (second column of Table 1). For all three measures, the correlation is positive and highly significant. Hence, the theoretical implication that as the share of private schooling increases, the quality of the public school should increase as well seems to be well supported in the U.S. data. The finding has important implications for the relationship of inequality and redistribution. If one looked only at aggregate spending, one might think that more inequality leads to less redistribution, as posited by Bénabou (2000), among others. However, the per-person transfer to poorer households (i.e., the education quality provided to households using public schools) does in fact go up. This is possible because more inequality leads to more targeted transfers, as richer households opt out of the public system.

The last row of Table 1 examines predictions for fertility rates. We find that states with more inequality and a higher share of private schooling have a lower fertility rate. This is in accordance with our model: parents economize on the number of children if the direct cost of education is high.

\footnotetext{
${ }^{21}$ The correlation is significant at the 10 percent level for total expenditure per student as well as mean teacher salary.
} 


\subsection{Determinants of fertility and public versus private school- ing at the household level}

We now examine the inner workings of our model more closely with the help of micro data from the U.S. Census. Our aim is to establish whether the model paints a realistic picture of the interaction between household income, private choices on education and fertility, and the quality of public schooling. This will be useful to assess whether our model indeed provides a plausible mechanism for generating the observed macro correlations. We draw on data on household income, family size (i.e., the household head's own children living in the household), public versus private schooling (for school-age children), and a number of demographic controls from the one-percent sample of the 2000 U.S. Census.

In the model, a household's decisions on fertility and private versus public schooling depend on two variables: income and the quality of public schooling (see Lemma 2 and the preceding discussion). In particular, richer households are predicted to be more likely to choose private schools and to have lower fertility rates. The strength of the income effect depends on the quality of public schooling; for example, if public schooling is of very high quality, even fairly rich households will use public schools. To examine these predictions, Tables 2 and 3 show regressions of family size and private schooling on household income and a number of controls. ${ }^{22}$ We use an ordered logit specification for the fertility choice and a logit specification for the private education choice. All regressions contain dummy variables for the age of the household head as well as the state of residence (the effect of further controls is discussed below).

The first column of each table presents results for regressions that only include household income in addition to the standard controls. As predicted by the theory, an increase in income is associated with a higher probability of using private schooling as well as lower fertility. ${ }^{23}$ However, in this specification the relation-

\footnotetext{
${ }^{22}$ In order to be able to include households that report zero income, we add $\$ 10$ to household income before taking logs. The results are qualitatively the same if we shift up incomes by $\$ 100$ or $\$ 500$ instead.

${ }^{23}$ The positive effect of income on the probability of private schooling has also been documented by Cohen-Zada and Justman (2003) and Epple, Figlio, and Romano (2004); see also Nechyba (2006). However, these studies no not consider fertility choices and the interaction of the quality of public schooling across states with income effects.
} 


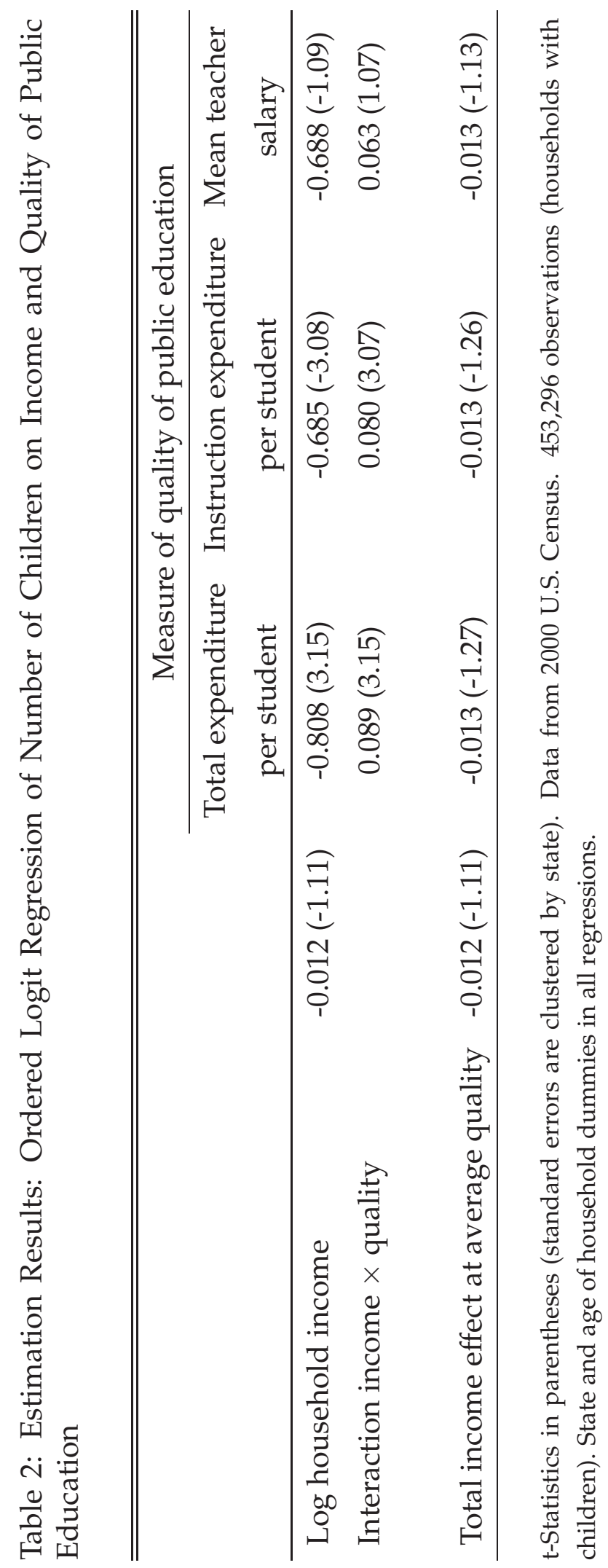




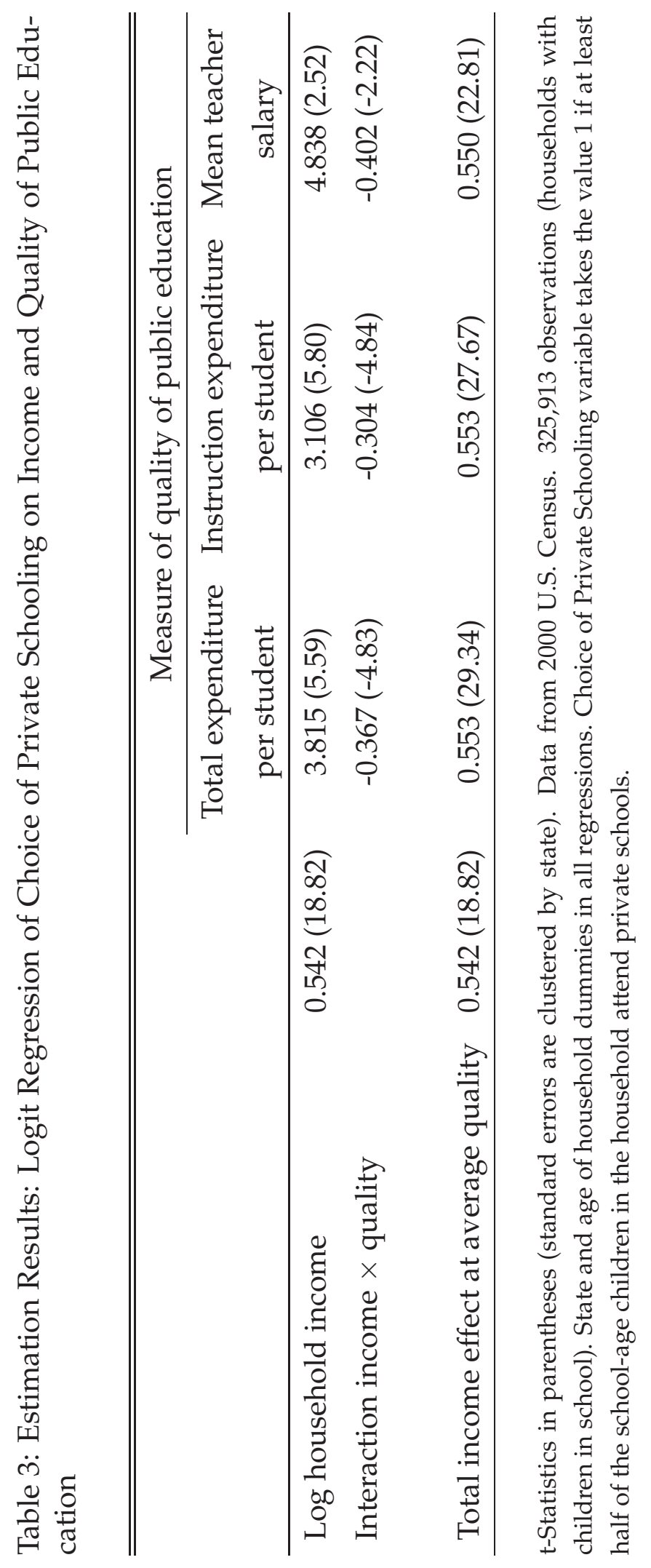


ship between household income and fertility is not significant at conventional levels. The remaining columns focus on the joint effect of household income and the quality of public schooling in determining private choices. Each regression contains an additional interaction term of household income with one of our three measures of the quality of public schooling. Notice that schooling quality is measured at the state level, not the household level. ${ }^{24}$ In essence, we are still estimating a micro relationship between household income and private choices, but we allow the slope of this relationship to vary systematically across states with a high and a low quality of public education. We find that in both regressions and for all three measures of the quality of public schooling, the estimated coefficient on the interaction term is of the opposite sign as the coefficient on income, which implies that the effect of income on household choices diminishes as the quality of public schooling goes up. When the interaction term is included, all parameter estimates are highly significant, with the one exception of the fertility regression using mean teacher salary as a quality measure.

The size of the interaction terms implies substantial variation in the steepness of the income-fertility and income-private schooling relationships across states with a low and high quality of public schooling. In the states with the highest quality of public education, these relationships are essentially flat. This is exactly what one should expect based on the theory: states with high-quality public schooling are close to a fully public regime, i.e., most parents use public schools regardless of income, and fertility varies little across income groups.

The regression results are robust with respect to a number of changes to the specification of the model. We have explored sensitivity to racial composition by estimating the regressions separately by race and by including race dummies, we have checked urban/rural differences by including a metropolitan area dummy, and we have run the regressions on restricted samples that limit the age range of the included households. Generally, the sign and significance of the interaction term in the two regressions is robust to these changes, as is the sign and significance of the total income effect in the education equation. The sign of the

\footnotetext{
${ }^{24}$ The fact that schooling quality is a state-level variable also precludes using it in the regression directly, because our regressions already contain state dummies. As a robustness test, we also carried out regressions without state dummies and schooling quality as an included variable, with overall similar results.
} 
total income effect in the fertility regression turns out to be more sensitive. In particular, for black and Hispanic households the total income effect is strongly negative, whereas for white households it is positive. However, when we restrict the sample to the ages 25-45, the total income effect is once again negative and significant. This suggests that for older white people, the slope of the relation between fertility and income can be reversed. ${ }^{25}$ However, even in the case of a positive slope, the sign of the interaction term is still the same.

\subsection{Inequality, fertility, and schooling across countries}

We now turn to the determinants of education systems across countries. Compared to our analysis of education in U.S. states, cross-country data pose additional difficulties. There are substantial differences in the level of development and in unobserved variables such as the political system, religious values etc. across countries which could have independent effects on the variables of interest. $^{26}$ Doing full justice to the arising empirical issues is beyond the scope of this paper. As a consequence, we focus on documenting the fundamental correlations and micro relationships implied by our theory.

The OECD provides internationally comparable data on the relative proportions of public and private investment in education for the period 1985-1998. In most countries, private sector expenditure is comprised mainly of household expenditures on tuition and other fees. The exception is Germany, where nearly all private expenditure is accounted for by contributions from the business sector to the system of apprenticeship at the upper secondary level. For primary and lower secondary education, there is little private funding in Germany. In 1998,

\footnotetext{
${ }^{25}$ To some extent, this finding could be due to the fact that in the Census, we only observe children who still live in the household. If rich, white households have children relatively late in life, they would appear to have unusually many children in their household at a time when other parents' children have already left to form their own households. This type of effect is not picked up by a simple age dummy, but can be partially addressed by restricting the age range of households included in the sample.

${ }^{26}$ The literature contains few empirical studies on the determinants of the mix between public and private education across countries. One exception is James (1993), who regresses private enrollments shares for 50 countries around 1980 on a number of determinants, and concludes that cultural factors such as religious competition and linguistic heterogeneity play an important role. However, the small number of observations compared to the number of explanatory variables casts some doubt on the robustness of the results.
} 


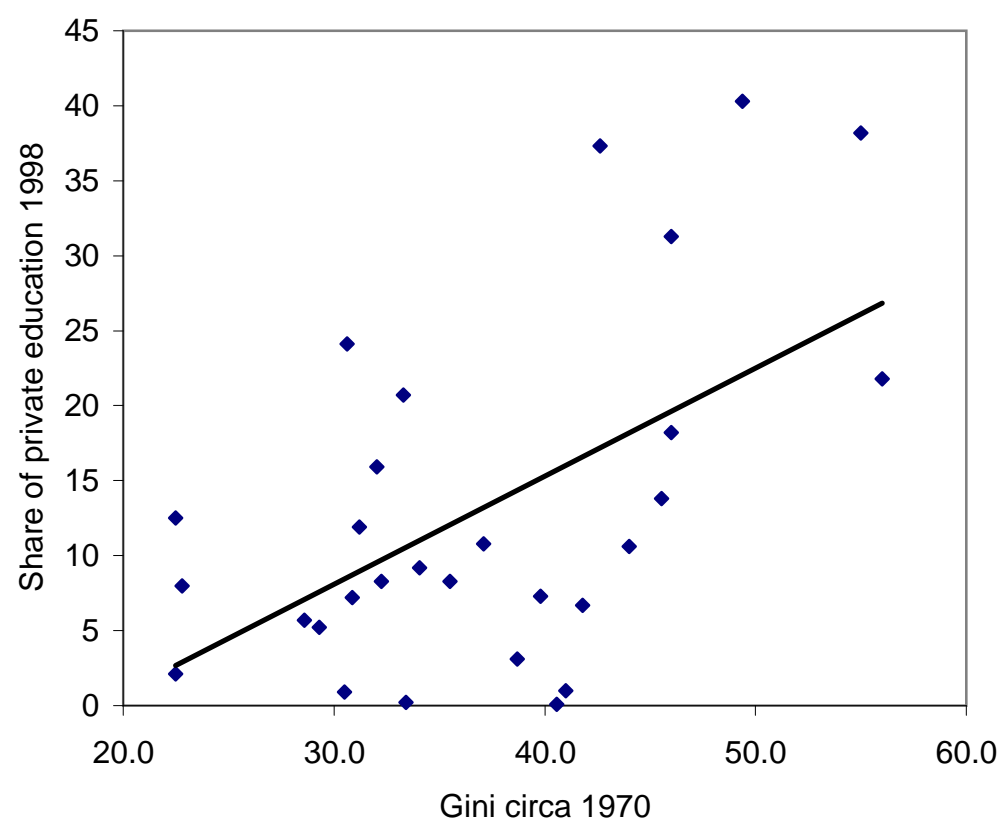

Figure 3: Inequality and education systems across countries

the data set contains information on a number of non-OECD countries (Israel, Uruguay, Czech Republic, Turkey, Argentina, Indonesia, Chile, Peru, Philippines, and Thailand). With observations on 31 countries, we can investigate whether inequality is a good predictor of private funding. Computing the correlation between the Gini coefficient for income inequality in 1970 (from Deininger and Squire 1996) and the share of private funding in 1998, we find that the correlation is positive and strong with a coefficient of 0.44 ( $\mathrm{t}$-stat $=2.64) .{ }^{27}$ The correlation increases to 0.55 ( $\mathrm{t}$-stat=3.55) if we consider only the primary and secondary levels of education. Figure 3 presents the cross plot of the private share in primary and secondary education with the Gini coefficient.

We next turn to micro data from the OECD Programme for International Student Assessment (PISA), which comprises data collected in the year 2000 on 15 yearold students in the principal industrialized countries. It includes a student questionnaire collecting information about the student's family and a school questionnaire that covers information on the extent of public funding and the public or private administration of schools. We focus on four variables in the PISA

\footnotetext{
${ }^{27}$ We use the Gini coefficient in 1970 to address possible reverse causality from schooling to inequality.
} 
database. The International Socioeconomic Index (ISEI) captures the attributes of occupations that converts parents' education into income. It was obtained by mapping parents' occupational codes onto an index of occupational status, developed by Ganzeboom, De Graaf, and Treiman (1992). This index provides a rough measure of household income and human capital (unfortunately, household income itself is not contained in the data base). Using the index, students are assigned to one of four social classes. ${ }^{28}$ The second student-specific variable in our data set is the number of siblings. At the school level, our data set contains information on the funding sources of schools and whether a school is publicly or privately run. For school funding, our variable is the percentage of total funding that stems from government sources, as opposed to fees paid by parents, benefactors, or other sources of income.

For each country, we have computed average school characteristics for the four social classes. For each group, we report the average share of education spending covered by public sources (the subsidization rate), the share of students in private schools, and the average fertility rate. The detailed results are provided in Appendix B. Overall, the findings are once again consistent with the theory: in the vast majority of cases, participation in private schooling increases and fertility decreases with social status.

An interesting feature of the PISA data is that it covers countries that appear to be characterized by different schooling regimes. In particular, a number of countries come close to what could be described as a fully public regime. To investigate the effects of having a fully public schooling regime, we define countries as fully public if the difference in the subsidization rate between the highest and lowest social class is less than five percent. ${ }^{29}$ The remaining countries are classified as

\footnotetext{
${ }^{28}$ Typical occupations in the lowest class (between 16 and 35 points on the ISEI scale) include small-scale farmer, metalworker, mechanic, taxi or truck driver, and waiter/waitress. Between 35 and 53 index points, the most common occupations are bookkeeping, sales, small business management, and nursing. As the required skills increase, so does the status of the occupation. Between 54 and 70 points, typical occupations are marketing management, teaching, civil engineering, and accounting. In the highest class (from 71 to 90 points), occupations include medicine, university teaching, and law.

${ }^{29}$ This group includes Hungary, the Czech Republic, Denmark, Finland, Germany, Iceland, Latvia, The Netherlands, Norway, Russia and Sweden. Appendix B also provides the proportion of students attending private schools. The school type is determined by the question "Is your school a public or a private school." Here public schools are those managed by a public
} 
being in the segregation regime. We also separately consider the five countries with the highest difference in the public subsidization rate of the lowest and the highest social class (Austria, Australia, Brazil, Mexico, and Spain). In this group, the difference between the subsidization rate of schools attended by members of the top and bottom social classes averages 25 percent.

Table 4 provides a number of statistics for the groups of countries with different education regimes. Not surprisingly, in the fully public group the level of public subsidization is particularly high with an average of 96 percent. These countries are also characterized by low income inequality (average Gini: 24.7), and the fertility differential between the bottom and top social classes is only $0.36 .{ }^{30} \mathrm{In}$ contrast, the group of countries in the segregation regime has an average Gini of 34.6 and a fertility differential of 0.47 . The five countries with the highest level of segregation also top the list in terms of inequality and differential fertility: the average Gini coefficient is 44.6 in this group, and the fertility differential between the bottom and top social classes amounts to 0.59 . The last row of Table 4 presents correlation coefficients between the Gini coefficient and the other variables across all countries in the data set. As predicted by the theory, in countries with higher income inequality average public funding is lower, the subsidization rate is more sensitive to social class, and fertility differentials are larger. ${ }^{31}$

\subsection{Public education spending and democracy}

We now turn to the final implication of our theory, namely the effect of democracy on education politics. Given that data on private spending on education

education authority, a government agency, or a governing board that is appointed either by the government directly or elected by public franchise. While we could have used this variable to define countries as fully public, for our purposes the public subsidization rate is a better indicator of public versus private schooling than the school type, because "private school" can mean different things in different countries. In Belgium, for example, most schools are nominally private, yet are entirely publicly funded. Nevertheless, using the school type variable instead of the school funding variable leads to similar results.

${ }^{30}$ In all the countries we find that the fertility of the lowest social class exceeds the fertility of the highest social group. In a majority of countries, the relationship between fertility and social status is monotonically decreasing; in some countries, it is U-shaped.

${ }^{31}$ One concern here is a reverse causality link whereby school segregation leads to more inequality. The problem is mitigated by the fact that we use Gini coefficients measured 20 years before the observed schooling outcomes. 


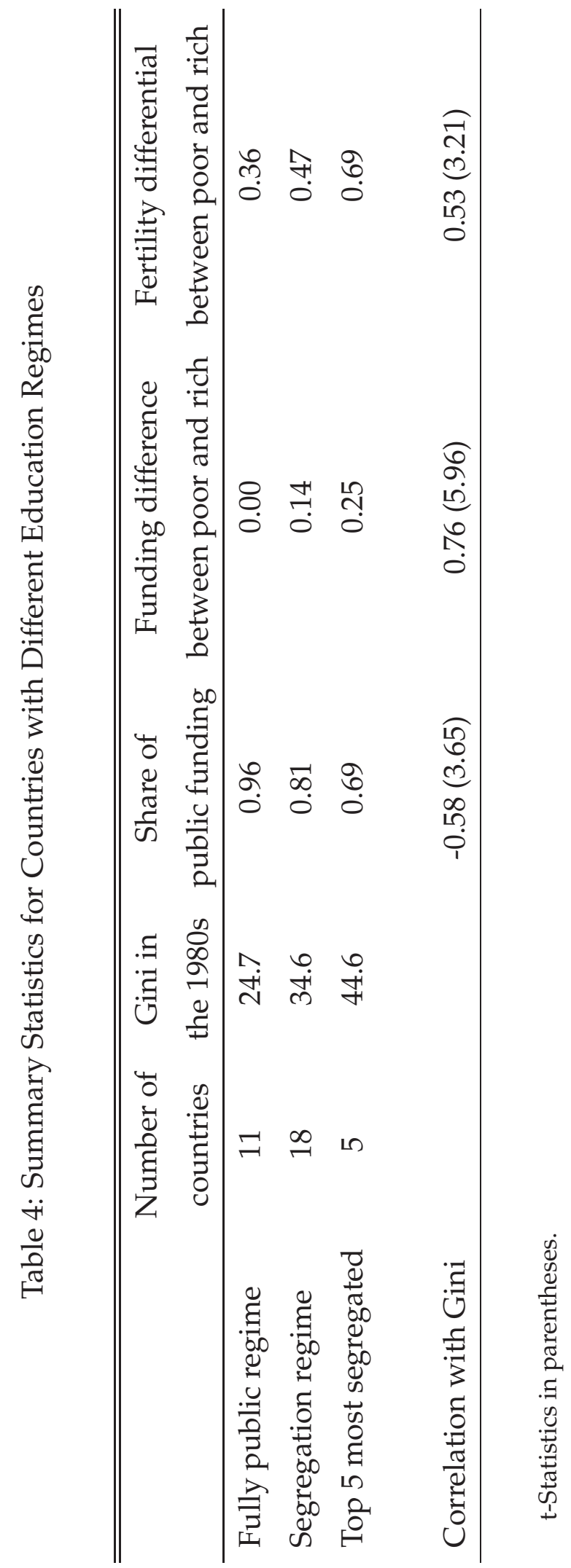


is available for only a few countries, we focus on public spending on education as a fraction of GDP. Here we have a sample of 158 countries covering the period 1970-2002 (with some missing observations; data from World Bank Development Indicators). We divide the sample into three groups, based on their level of democracy. As a democracy indicator, we use the political-rights index from the Freedom in the World Country Ratings. The index lies on a one-to-seven scale, with one representing the highest degree of freedom. We assign the countries into three groups, where "free" countries have an index of one, "partially free" have values from two to four, and "non-free" countries have values from five to seven.

Table 5 displays the mean and variance of public spending on education for the three groups of countries. The mean of spending is increasing with democracy, whereas the variance is decreasing. Figure 4 presents a density estimation of the entire distribution of public spending as a share of GDP for the three groups. The density for partially free and non-free countries displays a lower mean and a higher variance. Two-tailed tests of whether the differences are significant are provided in Table 6 . The mean in democratic (free) countries is significantly different from the one in the two other groups, and the variance in the non-free countries is significantly higher than in the partially free-countries, which is itself higher than in the free group. These findings are in line with the predictions of our theory for the case of an uneven distribution of political power (see Propositions 4 and 5). Clearly, our mechanism is not the only possible explanation for the observed high variance in public educations pending in non-democracies, but it is encouraging that the predictions of the model are in line with data along this dimension as well.

\section{Conclusions}

The education of its citizens is one of main areas of government intervention in every country in the world. At the same time, the government is generally not the only provider of education; education systems often display a juxtaposition of public and privately funded institutions. The degree of private involvement in the provision of education varies a great deal over different countries, going 
Table 5: Public Spending on Education in Democracies and Non-Democracies

\begin{tabular}{cccc}
\hline \hline Democracy index & Observations & Mean & Variance \\
\hline Free $(=1)$ & 1020 & 4.96 & 3.08 \\
Partially free $(1<x \leq 4)$ & 836 & 4.11 & 7.07 \\
Non-free $(4<x \leq 7)$ & 644 & 4.07 & 8.33 \\
\hline
\end{tabular}

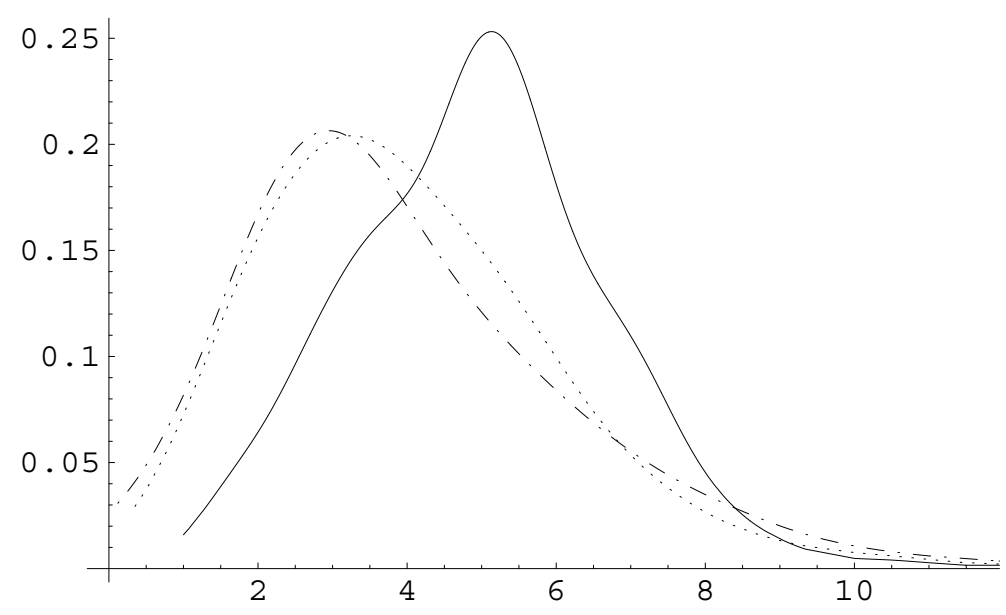

Legend: Free (solid line), partially free (dots), non-free (dashes). Note: Density estimation using the NonParametrix.m Package by Bernard Gress, 2004

Figure 4: Density of public education spending (percent of GDP)

Table 6: Mean and Variance Tests for Public Education Spending in Democracies and Non-Democracies

\begin{tabular}{cccccc}
\hline \hline & \multicolumn{2}{c}{ Mean difference test } & & \multicolumn{2}{c}{ Variance ratio test } \\
\cline { 2 - 3 } \cline { 5 - 6 } & Partially free & Non-free & & Partially free & Non-free \\
\hline Free & $0.85(0.00)$ & $0.89(0.00)$ & & $0.44(0.00)$ & $0.37(0.00)$ \\
Partially free & & $0.03(0.82)$ & & $0.85(0.03)$ \\
\hline
\end{tabular}

p-values in parentheses. 
from fully public systems as in some European countries to segregated systems as in parts of the United States. In this paper, we try to understand how countries choose the mix of public and private education.

We first conclude that high inequality maps into a segregated education system. In a segregated system, the quality of public schools is sufficiently low for rich households to prefer paying for private schools to enhance the education of their children. When inequality is low, on the other hand, the rich decide to send their children to public schools, so that they avoid paying for education twice (first through taxes, second through private schools). The prediction of a strong relationship between inequality and the extent of public schooling is in line with the empirical evidence. In both cross-country data and cross-state data in the U.S., we find that public spending on education is negatively related to income inequality.

Turning to the role of political power, we find that the quality and extent of public schooling generally increases with the political weight of the poor. In addition, if the poor are given at least equal weight in the political system, there is a unique equilibrium outcome. In societies that are politically dominated by the rich, on the other hand, multiple equilibria may arise. The reason is that when the rich are in charge, there is a complementarity between the number of rich people participating in public schools and their quality. For given initial conditions, such a country may either have a high-quality public schooling system in which many or all of the rich participate, or a low-quality system with all the rich using private schools. Despite the multiplicity, however, we find that spending on public education is never higher in a society dominated by the rich than in an otherwise identical economy where the poor have equal power. The model therefore provides an explanation for the observation that non-democratic countries spend on average a smaller fraction of GDP on public education than democracies, whereas the variance of spending across countries is higher among non-democracies.

While we have concentrated on cross-sectional evidence, another important question for future research is why public education was first introduced in the nineteenth century during the second phase of the Industrial Revolution. Galor and Moav (2006) argue that in this period capitalists started to have an interest in pub- 
lic education, because of complementarities between physical and human capital. Therefore, technological change strengthening this complementarity may have contributed to the introduction of public schooling. Galor, Moav, and Vollrath (2006) extend this analysis by distinguishing different sources of wealth. If land is less complementary to human capital than physical capital, a conflict of interest arises between land-owners and capitalists. The outcome of this conflict depends on the distribution of wealth and land-ownership.

In our model, public schooling always arises if political power is equally shared. The theory therefore points to the expansion of voting rights in the nineteenth century as a key explanation for the introduction of public schooling. This still leaves open the question why voting rights were expanded in the first place. The theory of Galor and Moav (2006) offers one potential explanation. Acemoglu and Robinson (2000), however, point in a different direction: the rich shared power in order to avoid the threat of a revolution. In either case, given that the poor did gain political influence, in our model the introduction of public schooling is a necessary consequence. Once public education is in place, the size of the public system depends on the evolution of the income distribution. To this end, the model points to the declining income inequality observed around the turn of the century as a potential explanation for the large expansion of public education that followed its initial introduction. 


\section{References}

Acemoglu, Daron and James A. Robinson. 2000. "Why Did the West Extend the Franchise? Democracy, Inequality and Growth in Historical Perspective." Quarterly Journal of Economics 115 (4): 1167-99.

Alderman, Harold, Peter F. Orazem, and Elizabeth M. Paterno. 2001. "School Quality, School Cost, and the Public/Private School Choices of Low-income Households in Pakistan." Journal of Human Resources 36 (2): 304-326.

Alesina, Alberto and Dani Rodrik. 1994. "Distributive Politics and Economic Growth." Quarterly Journal of Economics 109 (2): 465-90.

Bedi, Arjun S. and Ashish Garg. 2000. “The Effectiveness of Private versus Public Schools: The Case of Indonesia." Journal of Development Economics 61 (2): 463-494.

Bénabou, Roland. 1996. "Inequality and Growth." NBER Macroeconomics Annual, pp. 11-74.

_. 2000. "Unequal Societies: Income Distribution and the Social Contract." American Economic Review 90 (1): 96-129.

Bernheim, Douglas and Michael Whinston. 1986. "Menu Auctions, Resource Allocation, and Economic Influence." Quarterly Journal of Economics 101 (1): $1-31$.

Besley, Timothy and Stephen Coate. 1991. "Public Provision of Private Goods and the Redistribution of Income." American Economic Review 81 (4): 979-84.

Cohen-Zada, Danny and Moshe Justman. 2003. "The Political Economy of School Choice: Linking Theory and Evidence." Journal of Urban Economics 54 (2): 277-308.

Coughlin, Peter and Shmuel Nitzan. 1981. "Electoral Outcomes with Probabilistic Voting and Nash Social Welfare Maxima." Journal of Public Economics 15 (1): 113-21.

de la Croix, David and Matthias Doepke. 2003a. "Inequality and Growth: Why Differential Fertility Matters." American Economic Review 93 (4): 1091-113.

—. 2003b. "To Segregate or to Integrate: Education Politics and Democracy." UCLA Department of Economics Working Paper No. 831.

- 2004. "Public versus Private Education when Differential Fertility Matters." Journal of Development Economics 73 (2): 607-29.

Deininger, Klaus and Lyn Squire. 1996. "Measuring Income Inequality: A New Database." Development Discussion Paper No. 537, Harvard Institute for International Development. 
Diamond, Douglas W. and Philip H. Dybvig. 1983. "Bank Runs, Deposit Insurance, and Liquidity." Journal of Political Economy 91 (3): 401-19.

Doepke, Matthias and Fabrizio Zilibotti. 2005. “The Macroeconomics of Child Labor Regulation." American Economic Review 95 (5): 1492-524.

Epple, Dennis and Richard E. Romano. 1996a. "Ends Against the Middle: Determining Public Service Provision when there are Private Alternatives." Journal of Public Economics 62 (3): 297-325.

_ 1996b. "Public Provision of Private Goods." Journal of Political Economy 104 (1): 57-84.

Epple, Dennis, David Figlio, and Richard Romano. 2004. "Competition Between Private and Public Schools: Testing Stratification and Pricing Predictions." Journal of Public Economics 88 (7): 1215-45.

Fernández, Raquel and Richard Rogerson. 1995. "On the Political Economy of Education Subsidies." Review of Economic Studies 62 (2): 249-62.

Galor, Oded and Omer Moav. 2006. "Das Human-Kapital: A Theory of the Demise of the Class Structure." Review of Economic Studies 73 (1): 85-117.

Galor, Oded, Omer Moav, and Dietrich Vollrath. 2006. "Inequality in Land Ownership, the Emergence of Human Capital Promoting Institutions and the Great Divergence." Unpublished Manuscript, Brown University.

Ganzeboom, Harry B.G., Paul M. De Graaf, and Donald J. Treiman. 1992. “A Standard International Socio-Economic Index of Occupational Status." Social Science Research 21 (1): 1-56.

Glomm, Gerhard and Debra M. Patterson. 2002. "Endogenous Public Expenditures on Education." Unpublished Manuscript, Indiana University.

Glomm, Gerhard and B. Ravikumar. 1992. "Public Versus Private Investment in Human Capital: Endogenous Growth and Income Inequality." Journal of Political Economy 100 (4): 818-834.

_ 1998. “Opting Out of Publicly Provided Services: A Majority Voting Result." Social Choice and Welfare 15 (2): 197-99.

Goldhaber, Dan D. 1996. "Public and Private High Schools: Is School Choice the Answer to the Productivity Problem?" Economics of Education Review 15 (2): 93-109.

Gradstein, Mark and Moshe Justman. 1997. “Democratic Choice of an Education System: Implications for Growth and Income Distribution." Journal of Economic Growth 2 (2): 169-83.

Hassler, John, Jose V. Rodriguez Mora, Kjetil Storesletten, and Fabrizio Zilibotti. 2003. "The Survival of the Welfare State." American Economic Review 93 (1): $87-112$. 
James, Estelle. 1993. "Why Do Different Countries Choose a Different PublicPrivate Mix of Educational Sevices?" Journal of Human Resources 28 (3): 571592.

Katz, Michael L. and Carl Shapiro. 1985. "Network Externalities, Competition, and Compatibility." American Economic Review 75 (3): 424-440.

Kingdon, Geeta G. 1996. "The Quality and Efficiency of Private and Public Education: A Case-study of Urban India." Oxford Bulletin of Economics and Statistics 58 (1): 55-80.

Matsuyama, Kiminori. 1991. "Increasing Returns, Industrialization, and Indeterminacy of Equilibrium." Quarterly Journal of Economics 106 (2): 617-50.

Moav, Omer. 2005. "Cheap Children and the Persistence of Poverty." Economic Journal 115 (500): 88-110.

Neal, Derek. 1997. "The Effects of Catholic Secondary Schooling on Educational Achievement." Journal of Labor Economics 15 (1): 98-123.

Nechyba, Thomas J. 2006. "Income and Peer Quality Sorting Public and Private Schools." Chapter 22 of Handbook of the Economics of Education, Vol. 2, edited by Eric A. Hanushek and Finis Welch. Amsterdam: North-Holland.

Persson, Torsten and Guido Tabellini. 1994. "Is Inequality Harmful for Growth? Theory and Evidence." American Economic Review 84 (3): 600-21.

- 2000. Political Economics: Explaining Economic Policy. Cambridge, Massachusetts: MIT Press.

Ramsey, Frank P. 1927. "A Contribution to the Theory of Taxation." Economic Journal 37 (145): 47-61.

Ruggles, Steven, Matthew Sobek, Trent Alexander, Catherine A. Fitch, Ronald Goeken, Patricia Kelly Hall, Miriam King, and Chad Ronnander. 2004. "Integrated Public Use Microdata Series: Version 3.0." [Machine-readable database]. Minneapolis, MN: Minnesota Population Center.

Saint-Paul, Gilles and Thierry Verdier. 1997. "Power, Distributive Conflicts and Multiple Growth Paths." Journal of Economic Growth 2 (2): 155-168.

Stiglitz, Joseph E. 1974. "The Demand for Education in Public and Private School Systems." Journal of Public Economics 3 (4): 349-85.

Toma, Eugenia F. 1996. "Public Funding and Private Schooling Across Countries." Journal of Law and Economics 39 (2): 121-48.

Vandenberghe, Vincent and Stéphane Robin. 2003. "Does Private Education Matter? Recent Evidence from International OECD Data." Unpublished Manuscript, IRES, Université catholique de Louvain. 


\section{A Technical Appendix}

Proof of Lemma 1: From budget constraint (2) total spending on children is given by $x \phi n+n e$. Substituting either $n=n^{s}$ and $e=0$ or $n=n^{e}$ and $e=\eta \phi x /(1-\eta)$ yields that

$$
x \phi n+n e=\frac{\gamma}{1+\gamma} x .
$$

Taxable income therefore is

$$
x(1-\phi n)-n e=\frac{1}{1+\gamma} x .
$$

Proof of Lemma 2: We compute the level $x$ such that a household with income $x$ is indifferent between public and private by solving $u\left[x, v, n^{s}, 0,[E](s)\right]=$ $u\left[x, v, n^{e}, e, 0\right]$ :

$$
\tilde{x}=\frac{1-\eta}{\delta \phi \eta}[E](s) \quad \text { with: } \delta=(1-\eta)^{\frac{1}{\eta}} \cdot(6)
$$

$\tilde{x}$ is bigger than zero and depends positively on $[E](s)$. If $x$ is greater (resp. smaller) than $\tilde{x}, u\left[x, v, n^{s}, 0,[E](s)\right]$ is smaller (resp. greater) than $u\left[x, v, n^{e}, e, 0\right]$, and the household prefers private (resp. public) education, which proves the Lemma.

Proof of Proposition 1: The result follows from an application of the Brouwer fixed point theorem. Given (11), the equilibrium expected schooling quality $\mathrm{E}[\mathrm{s}]$ and actual quality $s$ lie in the interval:

$$
\mathrm{E}[s], s \in\left[\frac{\eta \phi}{1+\gamma \eta}, \eta \phi\right]
$$

We are now going to define a mapping $\Delta$ from $E[s]$ into $s$ which maps this interval into itself. Since an equilibrium requires $\mathrm{E}[s]=s$, a unique equilibrium exists if the mapping has unique fixed point.

Given expected schooling quality E[s], according to Lemma 2 and equation (7) the fraction of families participating in public education is given by:

$$
\Psi(\mathrm{E}[s])=\max \left\{\min \left\{\frac{1-\eta}{2 \sigma \delta \phi \eta} \mathrm{E}[s]-\frac{1-\sigma}{2 \sigma}, 1\right\}, 0\right\} .
$$

This function is (weakly) increasing in $\mathrm{E}[\mathrm{s}]$; the higher the expected quality of public education, the more parents are going to prefer using the public sector. 
We can now use (11) to map the expected education quality $\mathrm{E}[s]$ into the actual education quality $s$ that would result from the political system if fraction $\Psi(E[s])$ of families participated in the public system. This education quality $s=\Delta(\mathrm{E}[\mathrm{s}])$ is given by:

$$
\Delta(\mathrm{E}[s])=\frac{\eta \phi}{1+\gamma \eta \Psi(\mathrm{E}[s])}=\frac{\eta \phi}{1+\gamma \eta \max \left\{\min \left\{\frac{1-\eta}{2 \sigma \delta \phi \eta} \mathrm{E}[s]-\frac{1-\sigma}{2 \sigma}, 1\right\}, 0\right\}} .
$$

An equilibrium is characterized by a fixed point of $\Delta(\mathrm{E}[\mathrm{s}])$, i.e., a schooling level $s$ that satisfies $s=\Delta(s)$, so that the schooling quality $s$ that is expected by the parents is identical to the one actually implemented in the political process. Given (23), $\Delta$ is a continuous, weakly decreasing function mapping the closed interval given in (22) into itself. The mapping therefore crosses the 45-degree line exactly once, and a unique equilibrium exists.

Proof of Proposition 2: We first show that the private regime is not an equilibrium outcome. In a reductio ad absurdum argument, we would start by assuming the existence of such a case. We start from the optimal value of $s$ given in Equation (11). From this equation, we observe that as $\Psi$ tends to zero, $s$ tends to $\eta \phi$. With this quality of public schooling, the equilibrium income threshold (from Equation (6) is: $\tilde{x}[\eta \phi]=(1-\eta) / \delta$. For private education to be an equilibrium, this threshold should be lower than or equal to lowest income $1-\sigma$. Given the definition of $\delta=(1-\eta)^{1 / \eta}$, we have that $\delta<1-\eta$ which implies $x[\eta \phi]>1>1-\sigma$. Hence, with a quality of public schools going to $\eta \phi$, it is always optimal for the poorest person to chose public education. Therefore, the private regime cannot arise in equilibrium.

If the public regime is an equilibrium, it has $\Psi=1$ and $s=\eta \phi /(1+\gamma \eta$ ) (from Equation (11)). For this to be an equilibrium, we need the richest person to send his children to public school, which requires $\tilde{x}[\eta \phi /(1+\gamma \eta)] \geq 1+\sigma$. This condition can be written:

$$
\frac{1-\eta}{\delta(1+\gamma \eta)} \geq 1+\sigma .
$$

If $\gamma \geq \hat{\gamma}=(1-\delta-\eta) /(\delta \eta)$, the right hand side of the inequality is below 1 , and the inequality can never be satisfied. This condition links the taste for children $\gamma$ to the weight of education $\eta$ independently of $\sigma$. If $\gamma<\hat{\gamma}$, the above inequality can be rewritten as a condition on $\sigma$, which in the condition of the Proposition. It remains to show that $\gamma<\hat{\gamma} \Leftrightarrow \Psi>1 / 2$. $\Psi=1 / 2$ implies that the equilibrium is segregated. We solve for the equilibrium value of $\Psi$, which is given by:

$\Psi=\frac{-\gamma \delta \eta(1-\sigma)-2 \delta \sigma+\sqrt{8 \gamma \delta \eta \sigma(1-\delta(1-\sigma)-\eta)+(\gamma \delta \eta(1-\sigma)+2 \delta \sigma)^{2}}}{4 \gamma \delta \eta \sigma}$ 
There is only one value of $\gamma$ for which this big expression is equal to $1 / 2$, and it is $\hat{\gamma}$. Since $\Psi$ is a continuous function of $\gamma$, and that we already know that it can be equal to 1 for certain values of $\sigma$ if $\gamma<\hat{\gamma}$, we conclude that $\Psi>1 / 2$ for $\gamma<\hat{\gamma}$ and $\Psi<1 / 2$ for $\gamma>\hat{\gamma}$.

Proof of Proposition 3: In the interior regime (segregation), we have from (6) and (7):

$$
\Psi=\frac{\frac{1-\eta}{\delta \phi \eta} s-(1-\sigma)}{2 \sigma}
$$

Taking the derivative with respect to $s$, we obtain

$$
\frac{\partial \Psi}{\partial \sigma}=\frac{2 \sigma-2\left[\frac{1-\eta}{\delta \phi \eta} S-(1-\sigma)\right]}{2 \sigma}=\frac{1}{\sigma}\left(\frac{1}{2}-\Psi\right) .
$$

Hence,

$$
\text { If } \Psi \in(0,1), \quad \frac{\partial \Psi}{\partial \sigma}>0 \Leftrightarrow \Psi<\frac{1}{2} .
$$

In the public regime,

$$
\Psi=1, \quad \Rightarrow \quad \partial \Psi / \partial \sigma=0
$$

Proposition 2 together with (12), (24) and (25) imply Proposition 3.

Proof of Proposition 4: As in the proof of Proposition 1, we will proceed by analyzing the mapping from expected schooling quality $\mathrm{E}[s]$ into actual quality s. Given (16), a schooling quality of zero is now possible, so that $\mathrm{E}[s]$ and $s$ lie in the following interval:

$$
\mathrm{E}[s], s \in[0, \eta \phi]
$$

We are now going to define a mapping $\bar{\Delta}$ from $\mathrm{E}[s]$ into $s$ which maps this interval into itself. Since an equilibrium requires $\mathrm{E}[s]=s$, any equilibrium corresponds to a fixed point of the mapping.

Given expected schooling quality $\mathrm{E}[\mathrm{s}]$, according to Lemma 2 and equation (7) the fraction of families participating in public education is given by:

$$
\Psi(\mathrm{E}[s])=\max \left\{\min \left\{\frac{1-\eta}{2 \sigma \delta \phi \eta} \mathrm{E}[s]-\frac{1-\sigma}{2 \sigma}, 1\right\}, 0\right\} .
$$

This function is (weakly) increasing in $\mathrm{E}[s]$; the higher the expected quality of public education, the more parents are going to prefer using the public sector.

We can now use (16) to map the expected education quality $E[s]$ into the actual education quality $s$ that would result from the political system if fraction $\Psi(E[s])$ 
of families participated in the public system. This education quality $s=\bar{\Delta}(\mathrm{E}[s])$ is given by:

$$
\bar{\Delta}(\mathrm{E}[s])=\max \left\{\frac{\eta \phi(1-\sigma-\bar{x}+2 \sigma \Psi(\mathrm{E}[s]))}{\Psi(\mathrm{E}[s])(\gamma \eta(1-\sigma-\bar{x}+2 \sigma \Psi(\mathrm{E}[s]))+1+\sigma-\bar{x})}, 0\right\} .
$$

An equilibrium is characterized by a fixed point of $\bar{\Delta}(\mathrm{E}[\mathrm{s}])$, i.e., a schooling level $s$ that satisfies $s=\bar{\Delta}(s)$, so that the schooling quality $s$ that is expected by the parents is identical to the one actually implemented in the political process. Given $\Psi(\mathrm{E}[s])$ and the properties of (16) stated in the text, $\bar{\Delta}$ is a continuous function mapping the closed interval given in (26) into itself. Due to the Brouwer fixed point theorem, at least one equilibrium exists. Also notice that $\Psi=0$ is always an equilibrium, since $\bar{\Delta}(\mathrm{E}[0])=0$.

Now assume that conditions $\gamma<\hat{\gamma}$ and $\sigma<\hat{\sigma}$ are satisfied. We want to establish that in this case pure public schooling $\Psi=1$ is an equilibrium. In (28), the schooling quality corresponding to $\Psi=1$ is $s=\eta \phi /(1+\gamma \eta)$. The first term inside the minimization in (27) satisfies for this $s$ :

$$
\begin{aligned}
\frac{1-\eta}{2 \sigma \delta \phi \eta} s-\frac{1-\sigma}{2 \sigma} & =\frac{1-\eta}{2 \sigma \delta(1+\gamma \eta)}-\frac{1-\sigma}{2 \sigma} \\
& \geq \frac{1}{2\left(\frac{1-\eta}{\delta(1+\gamma \eta)}-1\right)}\left(\frac{1-\eta}{\delta(1+\gamma \eta)}-\left(2-\frac{1-\eta}{(1+\gamma \eta) \delta}\right)\right) \\
& =\frac{1}{\frac{1-\eta}{\delta(1+\gamma \eta)}-1}\left(\frac{1-\eta}{\delta(1+\gamma \eta)}-1\right)=1,
\end{aligned}
$$

where $\gamma<\hat{\gamma}$ guarantees that the right-hand side of the first equation is positive, and the inequality follows from $\sigma \leq \hat{\sigma}$. The public education education quality $s=\eta \phi /(1+\gamma \eta)$ is therefore mapped into $\Psi(s)=1$, which, in turn, implies $\Psi(s)=s$. Therefore, if pure public schooling is an equilibrium under an equal division of political power, it is still an equilibrium with a voting threshold $\bar{x}<$ $1-\sigma$. Since pure private schooling is always an equilibrium, we have at least two equilibria in this case. Next, notice that the slope of $\bar{\Delta}(s)$ is zero at $s=0$, since for sufficiently small $s$ we still have $\Psi=0$. Also, at $s=\eta \phi /(1+\gamma \eta)$ the slope of $\bar{\Delta}(s)$ is zero as well, since given $\sigma<\hat{\sigma}$ we have $\Psi=1$ in a neighborhood of $s=\eta \phi /(1+\gamma \eta)$. Given that $\bar{\Delta}(s)$ is continuous, it has to cross the 45-degree line at least one more time in between those values, implying the existence of a third equilibrium, which features segregation. 
Proof of Proposition 5: We have previously established that:

$$
\max \left\{\frac{\eta \phi}{\frac{(1+\sigma-\bar{x}) \Psi}{(1-\sigma-\bar{x}+2 \sigma \Psi)}+\gamma \eta \Psi}, 0\right\} \leq \frac{\eta \phi}{1+\gamma \eta \Psi},
$$

where the left-hand side is the schooling level that arises for a given $\Psi$ as a given by (16), and the right-hand side is the level that arises with equal political power as given by (11). Since the reverse mapping from a given schooling quality into $\Psi$ does not depend on the distribution of political power, this inequality implies that the mappings $\Delta$ and $\bar{\Delta}$ defined in the proofs of Propositions 1 and 4 satisfy $\bar{\Delta}(s) \leq \Delta(s)$. Equilibria in the two environments corresponds to levels of $s$ that satisfy $s=\bar{\Delta}(s)$ and $s=\Delta(s)$, respectively. It was established in the proof of Proposition 1 that $\Delta(s)$ is weakly decreasing and crosses the 45-degree line only once from above. Since $\bar{\Delta}(s) \leq \Delta(s)$, it then follows that $\bar{\Delta}$ cannot cross the 45 -degree line above the unique crossing point for $\Delta(s)$, so that we have $\bar{s} \leq s$. Finally, the relationship between $s$ and $v$ does not depend on the distribution of political power, and taxes are monotonically increasing in $s$, so that we have $\bar{v} \leq v$. 


\section{B PISA Data: Education, Fertility, and Social Status}

\begin{tabular}{|c|c|c|c|c|c|}
\hline Country & $\begin{array}{l}\text { Social } \\
\text { status }\end{array}$ & $\begin{array}{c}\text { Number of } \\
\text { observations }\end{array}$ & $\begin{array}{l}\text { Subsidization } \\
\text { rate } \\
\end{array}$ & $\begin{array}{c}\text { Percent in } \\
\text { private schools }\end{array}$ & Fertility \\
\hline \multirow[t]{4}{*}{ Australia } & $16-35$ & 939 & 76.95 & NA & 3.30 \\
\hline & $36-53$ & 1777 & 72.33 & NA & 3.05 \\
\hline & $54-70$ & 1607 & 65.04 & NA & 2.94 \\
\hline & $71-90$ & 542 & 58.77 & NA & 2.83 \\
\hline \multirow[t]{4}{*}{ Austria } & $16-35$ & 874 & 95.52 & 4.46 & 2.81 \\
\hline & $36-53$ & 2213 & 91.60 & 9.26 & 2.58 \\
\hline & $54-70$ & 992 & 86.19 & 16.23 & 2.40 \\
\hline & $71-90$ & 276 & 80.62 & 26.09 & 2.63 \\
\hline \multirow[t]{4}{*}{ Belgium } & $16-35$ & 1558 & 89.21 & 68.87 & 3.01 \\
\hline & $36-53$ & 2388 & 88.08 & 75.63 & 2.59 \\
\hline & $54-70$ & 1573 & 85.46 & 81.25 & 2.66 \\
\hline & $71-90$ & 516 & 84.76 & 83.33 & 2.75 \\
\hline \multirow[t]{4}{*}{ Brazil } & $16-35$ & 1699 & 87.93 & 2.35 & 3.67 \\
\hline & $36-53$ & 831 & 79.52 & 10.59 & 3.36 \\
\hline & $54-70$ & 926 & 66.77 & 23.00 & 3.07 \\
\hline & $71-90$ & 125 & 41.60 & 49.60 & 2.86 \\
\hline \multirow[t]{4}{*}{ Canada } & $16-35$ & 6502 & 90.36 & 0.00 & 3.07 \\
\hline & $36-53$ & 9536 & 89.94 & 0.00 & 2.84 \\
\hline & $54-70$ & 9006 & 87.83 & 0.00 & 2.81 \\
\hline & $71-90$ & 2302 & 85.12 & 0.00 & 2.86 \\
\hline \multirow[t]{4}{*}{ Czech Republic } & $16-35$ & 1064 & 93.07 & 7.33 & 2.81 \\
\hline & $36-53$ & 2741 & 94.06 & 6.20 & 2.48 \\
\hline & 54-70 & 1141 & 94.71 & 6.22 & 2.32 \\
\hline & $71-90$ & 309 & 95.25 & 6.47 & 2.19 \\
\hline \multirow[t]{4}{*}{ Denmark } & $16-35$ & 883 & 95.11 & 20.50 & 3.05 \\
\hline & $36-53$ & 1445 & 94.75 & 23.18 & 2.81 \\
\hline & $54-70$ & 1130 & 94.42 & 24.78 & 2.88 \\
\hline & $71-90$ & 271 & 94.50 & 25.46 & 2.87 \\
\hline \multirow[t]{4}{*}{ Finland } & $16-35$ & 1010 & 99.84 & 1.58 & 3.26 \\
\hline & $36-53$ & 1911 & 99.85 & 3.30 & 2.94 \\
\hline & $54-70$ & 1453 & 99.83 & 3.51 & 2.86 \\
\hline & $71-90$ & 381 & 99.78 & 4.72 & 2.88 \\
\hline \multirow[t]{4}{*}{ France } & $16-35$ & 1191 & 78.29 & 22.50 & 3.14 \\
\hline & $36-53$ & 1443 & 75.57 & 21.83 & 2.62 \\
\hline & $54-70$ & 929 & 73.36 & 20.67 & 2.61 \\
\hline & $71-90$ & 268 & 69.29 & 26.12 & 2.89 \\
\hline
\end{tabular}




\begin{tabular}{|c|c|c|c|c|c|}
\hline Country & $\begin{array}{l}\text { Social } \\
\text { status }\end{array}$ & $\begin{array}{c}\text { Number of } \\
\text { observations }\end{array}$ & $\begin{array}{l}\text { Subsidization } \\
\text { rate } \\
\end{array}$ & $\begin{array}{c}\text { Percent in } \\
\text { private schools }\end{array}$ & Fertility \\
\hline \multirow[t]{4}{*}{ Germany } & $16-35$ & 887 & 97.89 & 2.03 & 2.77 \\
\hline & $36-53$ & 1970 & 97.84 & 3.40 & 2.46 \\
\hline & $54-70$ & 1105 & 96.56 & 6.52 & 2.38 \\
\hline & $71-90$ & 357 & 96.11 & 7.84 & 2.46 \\
\hline \multirow[t]{4}{*}{ Greece } & $16-35$ & 1278 & 85.63 & 1.10 & 2.68 \\
\hline & $36-53$ & 1447 & 87.02 & 2.07 & 2.44 \\
\hline & $54-70$ & 1074 & 82.60 & 4.38 & 2.31 \\
\hline & $71-90$ & 280 & 72.52 & 15.71 & 2.24 \\
\hline \multirow[t]{4}{*}{ Hungary } & $16-35$ & 1022 & 85.76 & 3.82 & 2.74 \\
\hline & $36-53$ & 2070 & 86.68 & 4.01 & 2.42 \\
\hline & $54-70$ & 1281 & 88.20 & 3.51 & 2.30 \\
\hline & $71-90$ & 261 & 90.18 & 6.13 & 2.38 \\
\hline \multirow[t]{4}{*}{ Iceland } & $16-35$ & 572 & 99.58 & 0.00 & 3.80 \\
\hline & $36-53$ & 1300 & 99.52 & 0.62 & 3.46 \\
\hline & $54-70$ & 926 & 99.10 & 1.30 & 3.37 \\
\hline & $71-90$ & 364 & 98.82 & 1.92 & 3.46 \\
\hline \multirow[t]{4}{*}{ Ireland } & $16-35$ & 990 & 94.68 & 50.71 & 3.94 \\
\hline & $36-53$ & 1463 & 91.43 & 63.98 & 3.52 \\
\hline & $54-70$ & 1040 & 87.83 & 72.21 & 3.33 \\
\hline & $71-90$ & 183 & 81.23 & 78.69 & 3.25 \\
\hline \multirow[t]{4}{*}{ Italy } & $16-35$ & 1391 & 79.47 & 2.16 & 2.45 \\
\hline & $36-53$ & 1995 & 74.50 & 5.81 & 2.30 \\
\hline & $54-70$ & 896 & 74.53 & 5.80 & 2.22 \\
\hline & $71-90$ & 281 & 71.17 & 6.05 & 2.34 \\
\hline \multirow[t]{4}{*}{ Korea } & $16-35$ & 1554 & 53.63 & 47.23 & 2.46 \\
\hline & $36-53$ & 1840 & 48.12 & 50.00 & 2.25 \\
\hline & $54-70$ & 803 & 46.47 & 49.69 & 2.18 \\
\hline & $71-90$ & 96 & 42.19 & 45.83 & 2.20 \\
\hline \multirow[t]{4}{*}{ Mexico } & $16-35$ & 1607 & 44.74 & 3.17 & 4.33 \\
\hline & $36-53$ & 1134 & 40.15 & 17.20 & 3.74 \\
\hline & $54-70$ & 619 & 34.52 & 33.60 & 3.39 \\
\hline & $71-90$ & 222 & 29.87 & 49.55 & 2.95 \\
\hline \multirow[t]{4}{*}{ Netherlands } & $16-35$ & 480 & 94.93 & 72.92 & 3.09 \\
\hline & $36-53$ & 739 & 94.59 & 77.00 & 2.80 \\
\hline & $54-70$ & 807 & 93.86 & 76.70 & 2.79 \\
\hline & $71-90$ & 153 & 94.85 & 71.90 & 2.86 \\
\hline
\end{tabular}




\begin{tabular}{|c|c|c|c|c|c|}
\hline Country & $\begin{array}{l}\text { Social } \\
\text { status }\end{array}$ & $\begin{array}{c}\text { Number of } \\
\text { observations }\end{array}$ & $\begin{array}{l}\text { Subsidization } \\
\text { rate }\end{array}$ & $\begin{array}{c}\text { Percent in } \\
\text { private schools }\end{array}$ & Fertility \\
\hline \multirow[t]{4}{*}{ New Zealand } & $16-35$ & 643 & 84.82 & 0.78 & 3.56 \\
\hline & $36-53$ & 1275 & 81.16 & 3.61 & 3.20 \\
\hline & $54-70$ & 1041 & 78.20 & 5.86 & 3.07 \\
\hline & $71-90$ & 339 & 73.19 & 12.39 & 2.86 \\
\hline \multirow[t]{4}{*}{ Norway } & $16-35$ & 418 & 99.57 & 0.72 & 3.40 \\
\hline & $36-53$ & 1737 & 99.71 & 0.63 & 2.98 \\
\hline & $54-70$ & 1148 & 99.53 & 1.13 & 2.99 \\
\hline & $71-90$ & 538 & 99.39 & 1.12 & 2.95 \\
\hline \multirow[t]{4}{*}{ Poland } & $16-35$ & 1052 & 94.78 & 0.38 & 3.07 \\
\hline & $36-53$ & 1449 & 92.08 & 2.00 & 2.75 \\
\hline & $54-70$ & 564 & 91.24 & 4.08 & 2.49 \\
\hline & $71-90$ & 156 & 82.51 & 13.46 & 2.45 \\
\hline \multirow[t]{4}{*}{ Portugal } & $16-35$ & 1843 & 89.10 & 7.27 & 2.67 \\
\hline & $36-53$ & 1501 & 86.67 & 6.46 & 2.33 \\
\hline & $54-70$ & 747 & 83.58 & 8.17 & 2.23 \\
\hline & $71-90$ & 278 & 77.73 & 7.55 & 2.28 \\
\hline \multirow[t]{4}{*}{ Russia } & $16-35$ & 1594 & 94.19 & 0.00 & 2.91 \\
\hline & $36-53$ & 2742 & 93.38 & 0.00 & 2.71 \\
\hline & $54-70$ & 1135 & 92.94 & 0.00 & 2.66 \\
\hline & $71-90$ & 828 & 94.15 & 0.00 & 2.44 \\
\hline \multirow[t]{4}{*}{ Spain } & $16-35$ & 2078 & 90.92 & 24.01 & 2.60 \\
\hline & $36-53$ & 2020 & 82.93 & 42.48 & 2.36 \\
\hline & $54-70$ & 902 & 73.21 & 55.21 & 2.40 \\
\hline & $71-90$ & 387 & 59.13 & 68.22 & 2.50 \\
\hline \multirow[t]{4}{*}{ Switzerland } & $16-35$ & 1290 & 98.28 & 2.56 & 2.93 \\
\hline & $36-53$ & 2398 & 96.20 & 5.50 & 2.58 \\
\hline & $54-70$ & 1351 & 93.73 & 8.44 & 2.54 \\
\hline & $71-90$ & 582 & 89.72 & 13.40 & 2.68 \\
\hline \multirow[t]{4}{*}{ United Kingdom } & $16-35$ & 1858 & 98.24 & 0.65 & 3.44 \\
\hline & $36-53$ & 3166 & 96.50 & 2.46 & 2.99 \\
\hline & $54-70$ & 2276 & 89.99 & 8.92 & 2.82 \\
\hline & $71-90$ & 856 & 84.93 & 14.02 & 2.82 \\
\hline \multirow[t]{4}{*}{ United States } & $16-35$ & 584 & 94.01 & 4.11 & 3.80 \\
\hline & $36-53$ & 840 & 92.42 & 5.12 & 3.54 \\
\hline & $54-70$ & 899 & 92.84 & 5.01 & 3.10 \\
\hline & $71-90$ & 202 & 87.18 & 7.92 & 3.02 \\
\hline
\end{tabular}

